\title{
Regulatory principles governing Salmonella and Yersinia virulence
}

\author{
Marc Erhardt ${ }^{1}$ and Petra Dersch ${ }^{2 *}$ \\ ${ }^{1}$ Young Investigator Group Infection Biology of Salmonella, Helmholtz Centre for Infection Research, Braunschweig, \\ Germany, ${ }^{2}$ Department of Molecular Infection Biology, Helmholtz Centre for Infection Research, Braunschweig, Germany
}

\section{OPEN ACCESS}

Edited by:

Dongsheng Zhou,

Beijing Institute of Microbiology and Epidemiology, China

Reviewed by:

Amit Kumar Tyagi,

The University of Texas MD Anderson

Cancer Center, USA

James M. Slauch,

University of Illinois, USA

${ }^{*}$ Correspondence:

Petra Dersch,

Department of Molecular Infection Biology, Helmholtz Centre for Infection

Research, Inhoffenstrasse 7, 38124 Braunschweig, Germany petra.dersch@helmholtz-hzi.de

Specialty section:

This article was submitted to

Food Microbiology,

a section of the journal

Frontiers in Microbiology

Received: 30 June 2015

Accepted: 27 August 2015

Published: 09 September 2015

Citation:

Erhardt M and Dersch P (2015)

Regulatory principles governing

Salmonella and Yersinia virulence.

Front. Microbiol. 6:949.

doi: 10.3389/fmicb.2015.00949
Enteric pathogens such as Salmonella and Yersinia evolved numerous strategies to survive and proliferate in different environmental reservoirs and mammalian hosts. Deciphering common and pathogen-specific principles for how these bacteria adjust and coordinate spatiotemporal expression of virulence determinants, stress adaptation, and metabolic functions is fundamental to understand microbial pathogenesis. In order to manage sudden environmental changes, attacks by the host immune systems and microbial competition, the pathogens employ a plethora of transcriptional and posttranscriptional control elements, including transcription factors, sensory and regulatory RNAs, RNAses, and proteases, to fine-tune and control complex gene regulatory networks. Many of the contributing global regulators and the molecular mechanisms of regulation are frequently conserved between Yersinia and Salmonella. However, the interplay, arrangement, and composition of the control elements vary between these closely related enteric pathogens, which generate phenotypic differences leading to distinct pathogenic properties. In this overview we present common and different regulatory networks used by Salmonella and Yersinia to coordinate the expression of crucial motility, cell adhesion and invasion determinants, immune defense strategies, and metabolic adaptation processes. We highlight evolutionary changes of the gene regulatory circuits that result in different properties of the regulatory elements and how this influences the overall outcome of the infection process.

Keywords: virulence regulation, pathogenicity factors, motility, transcription factors, post-transcriptional modifications, environmental control systems regulatory RNAs, riboswitches, metabolic adaptation

\section{Introduction}

Gastrointestinal infections by pathogenic Enterobacteriaceae represent a serious economic and health problem worldwide. They cause severe diarrheal diseases, which are still a leading cause of death among children under five. In developed countries, the incidence of foodborne outbreaks is less problematic, but remains substantial and constitutes a significant socioeconomic burden. Globalization of food supply, introduction and persistence of the pathogens in unknown environmental niches, frequent environmental changes leading to rapid evolution of newly emerging variants, and the development of antibiotic-resistant Enterobacteriaceae which use the intestinal tract as main reservoir are reasons why foodborne intestinal diseases by these pathogens remain a global public health problem. The worldwide rise of antibiotic-resistant strains represents a serious threat for the treatment of gastrointestinal pathogens. Furthermore, antibiotic therapies of most gastrointestinal infections are (i) ineffective as they are unable to improve clinical symptoms or shorten duration of shedding, are (ii) skewing of the intestinal commensal community (dysbiosis) which was found to support inflammatory diseases, e.g., by 
enteric pathogens or other usually harmless commensals, and are (iii) associated with an increased risk of serious complications in cases such as enterohemorrhagic Escherichia coli (EHEC).

Many cases of gastrointestinal infections in Europa and North America are caused by members of the genus Salmonella and Yersinia. The enteric representatives of both genera are gramnegative, facultative anaerobic and motile bacteria, which are usually transmitted by infected animals, or contaminated food or water via the fecal-oral route. Enteropathogenic Salmonella and Yersinia species can occupy many different environmental habitats, persist in certain domestic and wild animal reservoir hosts (in particular cattle, swine, poultry, wild birds, pet reptiles), and are routinely isolated from ground water, soil, plants, and insects (Fredriksson-Ahomaa et al., 2006; Hoelzer et al., 2011; Fredriksson-Ahomaa, 2012; Wiedemann et al., 2014). Undercooked chicken and eggs are considered the major infection source of salmonellae, whereas undercooked pork, vegetables, and lettuce are responsible for most Yersinia infections (Hoelzer et al., 2011; Fredriksson-Ahomaa, 2012). Enteric Salmonella and Yersinia species cause various gutassociated symptoms (e.g., enteritis, ileitis, colitis, vomitting, intestinal cramping, and inflammatory diarrhea), and in rare cases they can lead to systemic infections and induce extraintestinal sequelae such as fatal respiratory, hepatic, spleen, and/or neurological damage, erythema nodosum and reactive arthritis (Bottone, 1999; Koornhof et al., 1999; Ohl and Miller, 2001). Inflammatory diarrhea, which is typically associated with the highly invasive Yersinia species $Y$. enterocolitica and $Y$. pseudotuberculosis, and enteroinvasive Salmonella serotypes is characterized by an acutely increased vascular permeability and the recruitment of neutrophils which result in the formation of tissue exudates and necrotic lesions (Autenrieth and Firsching, 1996; Tsolis et al., 2008). Invasion of the bacteria from the intestinal tract into underlying lymphatic follicles (Peyer's patches) can lead to the ulceration of the tissue and abdominal pain that mimics appendicitis. The detection of the invasive bacteria by the innate immune system also results in the production of pyrogenic cytokines (IL- $1 \beta$, IL- 6, TNF- $\alpha$ and interferons) that increase the host's body temperature (typhoid/enteric fever) (Tsolis et al., 2008; Gu et al., 2013).

Enteric Yersinia and Salmonella serotypes are well adapted for survival in a variety of external environments and persistence in various host animals. The bacteria adjust rapidly to several extremely different and stressful environments during the invasion process, such as gastric acidity, increased osmolarity, changing nutrient/ion availability, and competition with the host's microbiota in the intestine (Fabrega and Vila, 2013; Heroven and Dersch, 2014). In order to succeed in invading the host, they employ a wide variety of virulence factors, such as flagella, host colonization factors (fimbriae, adhesins/invasins), and many secreted toxins and effector proteins. These molecules are needed to propel the bacteria to target cells, attach to, infect and survive inside host cells and protect the pathogen against host immune responses (Figure 1). To establish a successful infection, process, these virulence factors and adequate metabolic pathways must be expressed at the correct spatiotemporal conditions. Consequently, a substantial cross-talk between different pathogenicity elements and physiological adaptation processes has to exist. The correct spatiotemporal expression of the various virulence constituents is achieved by regulation at the transcriptional, post-transcriptional and posttranslational levels by a myriad of transcription factors, nucleoidassociated proteins, regulatory small RNAs (sRNAs) and RNases. Moreover, a growing set of small signaling molecules and different proteases controls the activity of enzymes and virulencerelevant factors during the infection process. The majority of the contributing regulators and control mechanisms are highly conserved between salmonellae and yersiniae, but the regulatory network composition and architecture are often changed. In the following chapters we will compare regulatory factors and global networks controlling early and late stages of the infection process of Salmonella and Yersinia to highlight conserved regulatory elements, but also changes that provided an important source for the divergence of the different genera with respect to their virulence-relevant physiological and pathogenic properties.

\section{Regulatory Circuits Controlling Early Stages of Host Colonization}

\section{Survival in the Intestinal Lumen}

The gastrointestinal tract of mammals is a rich source of food for enteric pathogens as it contains a large variety of simple and polymeric sugars, amino acids, peptides, and proteins, as well as lipids and other carbon- and nitrogen-containing metabolites. The availability of the nutrients varies significantly between hosts, different sections of the intestinal tract and different stages of the infection process, as it depends strongly on (i) the diet of the host, (ii) the composition and activity of the intestinal microbiota, which includes $10^{14}$ well-adapted bacteria from more than 400 species, (iii) absorption by the intestinal cells, and (iv) inflammation and hypoxic conditions induced by the host immune response during the progress of an infection (Nizet and Johnson, 2009; Rohmer et al., 2011). Moreover, the host limits the pathogen's access to essential ions, including magnesium, iron, and zinc (Brown et al., 2008; Abu Kwaik and Bumann, 2013; Zhang and Rubin, 2013). Consequently, Salmonella and Yersinia must either grow on non-utilized energy sources or metabolic end products, or metabolize nutrients and import ions much more efficiently to ensure maximal fitness and competiveness against the intestinal microbiota.

An important common characteristic of enteropathogenic Salmonella and Yersinia strains is that they possess a highly complex metabolism with many redundant or alternative catabolic and biosynthetic pathways. This allows them to utilize a large variety of organic energy sources and renders them very flexible and robust against sudden changes of nutrient availability. Another basis for their success is their ability to select the best energy sources among provided nutrients to gain the most benefit for lowest costs to optimize their biological fitness (Dandekar et al., 2014; Heroven and Dersch, 2014). Furthermore, they possess a plethora of sophisticated sensing and signal transduction strategies to adapt to variation in 


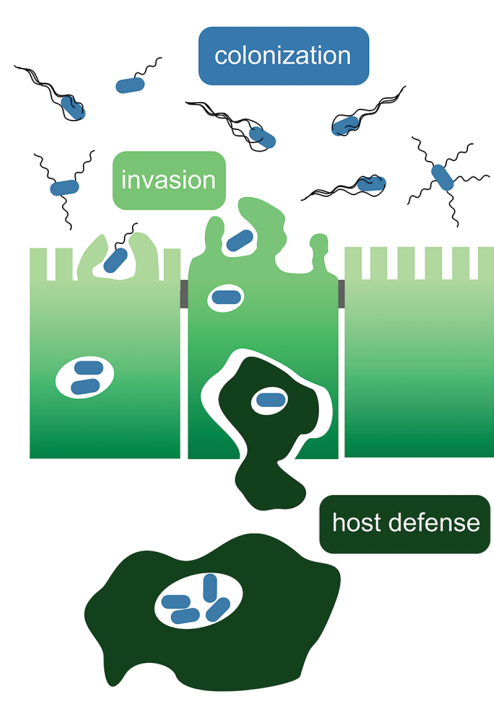

Salmonella enterica serovar Typhimurium

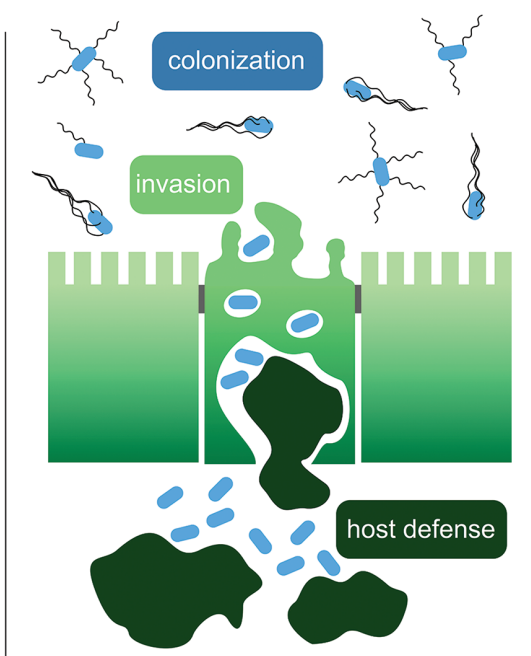

Yersinia enterocolitica

Yersinia pseudotuberculosis

FIGURE 1 | The course of infection by enteric Yersinia species and Salmonella enterica serovar Typhimurium. Enteropathogenic Salmonella Typhimurium utilizes flagellar motility for host colonization in the gut lumen and directed movement toward the epithelial layer. Salmonella attaches to the intestinal epithelium using a variety of adhesins and secretion of effector proteins via the Spi-1 encoded injectisome device for invasion of M cells or other enterocytes. The bacteria survive and replicate within Salmonella-containing vacuoles inside epithelial cells and phagocytes. The enteropathogenic Yersinia species Y. enterocolitica and

Y. pseudotuberculosis are ingested via contaminated food and enter the lymphatic system through the M cells in the small intestine. In the lymphatic tissues they reside predominantly outside of the cells.

the nutrient composition during the course of an infection. Moreover, a large number of conserved regulatory proteins has been identified over the past years, which are implicated in metabolic control (Table 1), and a steadily increasing number of post-transcriptional control systems, including non-coding RNAs, and small signaling molecules such as ppGpp, cAMP, and c-di-GMP has been identified as additional elements controlling virulence and metabolism.

\section{Sensing Intestinal Stimuli by Two-Component Regulatory Systems}

External stimuli, which are relevant for metabolic adaptation and virulence are frequently sensed by bacterial two component systems (TCSs) and converted into an adaptive cellular response. Among the most virulence-relevant TCS are the pleiotropic PhoP/PhoQ, EnvZ/OmpR, and BarA/SirA(UvrY) systems (Groisman, 2001; Groisman and Mouslim, 2006) (Figures 2 and 3). They are composed of the membranebound sensor kinases PhoQ, EnvZ, and BarA that sense the environmental signals and phosphorylate the cytoplasmic response regulator PhoP, OmpR, and UvrY(SirA). The TCS $\mathrm{PhoP} / \mathrm{PhoQ}$ responds to low magnesium, low $\mathrm{pH}$ environments, and host-secreted cationic antimicrobial peptides (Groisman, 2001). The global regulator PhoP controls a very complex network of genes, whereby the individual Yersinia and Salmonella PhoP regulons have considerable differences: (i) in the molecular architecture of the regulatory sequences and promoters, and (ii) in amino acid alterations in the conserved $\mathrm{PhoP}$ regulator itself. This enables both PhoP response regulators to retain the ability to transcribe the core members of the regulon in both pathogens and also allows inclusion of newly acquired genes into the ancestral regulatory circuit (Perez and Groisman, 2009). In Salmonella, the PhoP/PhoQ system is essential for virulence and survival within macrophages (Miller et al., 1989). The response regulator PhoP represses hilA and the prg (PhoPrepressed genes) genes (Pegues et al., 1995; Bajaj et al., 1996), whereas transcription of $\underline{P h o P}$-activated genes ( $p a g)$ required for survival within macrophages is activated (Miller et al., 1989; Belden and Miller, 1994). PhoP also controls expression of Salmonella pathogenicity island-2 (Spi-2) by binding to the $s s r B$ promoter region and the $5^{\prime}$-UTR of the spiR transcript (Belden and Miller, 1994). In contrast, in yersiniae the PhoP/PhoQ system has been found to promote proliferation of human pathogenic yersiniae within professional phagocytes in vitro, but its role during pathogenesis is less defined (Grabenstein et al., 2004, 2006; Flamez et al., 2007). Recent studies indicate that strainspecific differences that remodel expression of PhoP-dependent control functions appear to influence the overall outcome of the virulence phenotype (Grabenstein et al., 2004; Bozue et al., 2011; Nuss et al., 2014; Pisano et al., 2014). The PhoP/PhoQ system of Yersinia was shown to control modification of lipid A linked to antimicrobial peptide resistance and promotes survival and proliferation in macrophages and neutrophils (Grabenstein et al., 2004; Reines et al., 2012). Another important virulence control system, which is under PhoP/PhoQ control, is the carbon storage regulator (Csr) system coordinating the expression of important Yersinia adhesion factors (e.g., invasin), motility and multiple virulence-relevant metabolic pathways (see also Conclusion and 
TABLE 1 | Comparison of the protein homology of major regulatory factors of Salmonella enterica serovar Typhimurium (ST) and Yersinia pseudotuberculosis (Ypt) using Basic Local Alignment Search Tool (BLAST) analysis.

\begin{tabular}{|c|c|c|c|c|c|c|c|}
\hline $\begin{array}{l}\text { Gene name } \\
\text { ST strain LT2 }\end{array}$ & $\begin{array}{l}\text { Locus tag ST } \\
\text { strain LT2 }\end{array}$ & $\begin{array}{l}\text { Gene name Ypt } \\
\text { strain YPIII }\end{array}$ & $\begin{array}{l}\text { Locus tag Ypt } \\
\text { strain YPIII }\end{array}$ & $\begin{array}{l}\text { Sequence } \\
\text { coverage (\%) }\end{array}$ & $\begin{array}{l}\text { Amino acids } \\
\text { identity (\%) }\end{array}$ & $\begin{array}{l}\text { Mode of } \\
\text { regulation }\end{array}$ & Virulence pathway \\
\hline BarA & STM2958 & BarA & YPK_3451 & 99 & 59 & TCS & $\begin{array}{l}\text { Colonization, } \\
\text { invasion, host } \\
\text { defense }\end{array}$ \\
\hline ClpP & STM0448 & ClpP & YPK_3234 & 100 & 89 & Protease & Colonization, invasion \\
\hline CpxA/CpxS & STM4058 & CpxA & YPK_4133 & 99 & 81 & TCS & Host defense \\
\hline CsrA & STM2826 & CsrA & YPK_3372 & 100 & 95 & Translation & $\begin{array}{l}\text { Colonization, } \\
\text { invasion, host } \\
\text { defense }\end{array}$ \\
\hline Dam & STM3484 & dam & YPK_0228 & 96 & 70 & Translation & Invasion \\
\hline FimZ & STM0549 & & YPK_2269 & 98 & 48 & Transcription & Colonization \\
\hline FimZ & STM0549 & & YPK_2499 & 98 & 31 & & \\
\hline Fis & STM3385 & Fis & YPK_0452 & 100 & 98 & Transcription & $\begin{array}{l}\text { Colonization, } \\
\text { invasion, host } \\
\text { defense }\end{array}$ \\
\hline FlhC & STM1924.S & FlhC & YPK_1746 & 100 & 82 & Transcription & Colonization \\
\hline FlhD & STM1925 & FlhD & YPK_1745 & 97 & 76 & Transcription & Colonization \\
\hline FliA & STM1956 & FliA & YPK_2380 & 99 & 83 & Transcription & Colonization, invasion \\
\hline FliT & STM1962 & FliT & YPK_2384 & 85 & 36 & Protein stability & Colonization \\
\hline FliZ & STM1955 & Fliz & YPK_2378 & 91 & 55 & $\begin{array}{l}\text { Transcription, } \\
\text { translation }\end{array}$ & Colonization, invasion \\
\hline H-NS & STM1751 & $\mathrm{H}-\mathrm{NS}$ & YPK_2074 & 98 & 87 & Transcription & $\begin{array}{l}\text { Colonization, } \\
\text { invasion, host } \\
\text { defense }\end{array}$ \\
\hline $\mathrm{HilC} / \mathrm{SirC}$ & STM2867 & & NA & NA & NA & Transcription & Invasion \\
\hline HilD & STM2875 & & NA & NA & NA & Transcription & $\begin{array}{l}\text { Colonization, } \\
\text { invasion, host } \\
\text { defense }\end{array}$ \\
\hline HilE & STM4509.S & & YPK_0803 & 83 & 30 & Protein activity & Invasion \\
\hline IhfA & STM1339 & & YPK_1826 & 98 & 94 & Transcription & Host defense \\
\hline $\operatorname{lnvF}$ & STM2899 & & NA & NA & NA & Transcription & Invasion \\
\hline IscR/ YfhP & STM2544 & IscR & YPK_1275 & 88 & 79 & Transcription & Host defense \\
\hline Lon & STM0450 & Lon & YPK_3232 & 100 & 91 & Protease & Colonization, invasion \\
\hline LrhA & STM2330 & RovM & YPK_1559 & 92 & 72 & Transcription & Colonization, invasion \\
\hline NA & NA & LcrQ/YscM & pYV0089 & NA & NA & Translation & Host defense \\
\hline NA & NA & YopD & pYV0054 & NA & NA & Translation & Host defense \\
\hline OmpR & STM3502 & OmpR & YPK_0172 & 100 & 99 & TCS & $\begin{array}{l}\text { Colonization, } \\
\text { invasion, host } \\
\text { defense }\end{array}$ \\
\hline PhoB & STM0397 & PhoB & YPK_3276 & 100 & 90 & TCS & Colonization, invasion \\
\hline PhoP & STM1231 & PhoP & YPK_1715 & 99 & 79 & TCS & $\begin{array}{l}\text { Invasion, host } \\
\text { defense }\end{array}$ \\
\hline PhoQ & STM1230 & PhoQ & YPK_1714 & 96 & 62 & TCS & $\begin{array}{l}\text { Invasion, host } \\
\text { defense }\end{array}$ \\
\hline
\end{tabular}


TABLE 1 | Continued

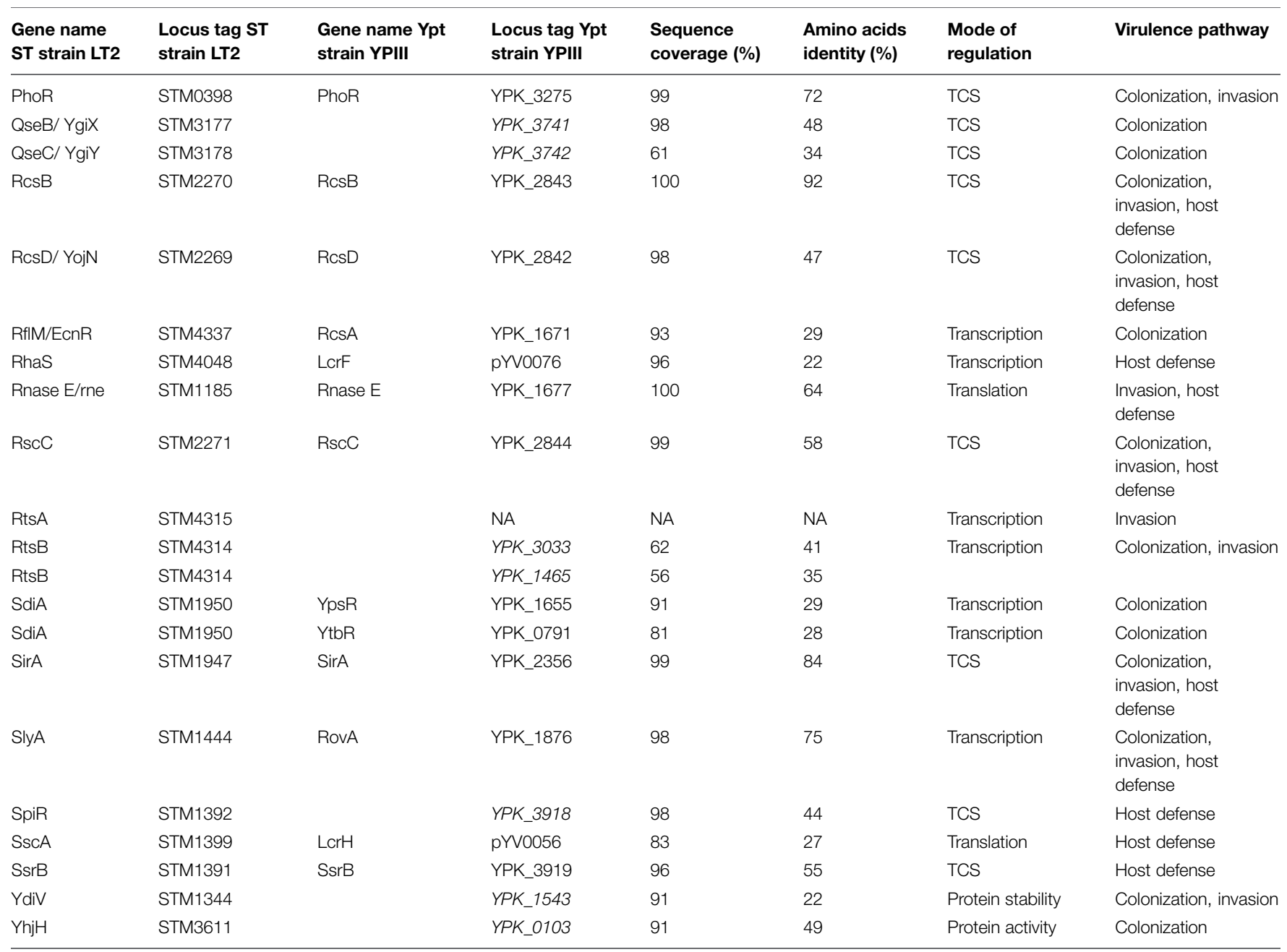

Sequence coverage reports the length of the identified homologous protein sequence with the indicated amino acid identity. In the majority, the true orthologs of the query protein sequences are listed, whereas close homologs with unknown regulatory function and low sequence identity are given in italics. NA = not available.

Outlook; Heroven et al., 2008; Bücker et al., 2014; Nuss et al., 2014).

The TCS OmpR/EnvZ was originally identified as regulator system controlling the outer membrane porins in response to osmolarity and temperature, but later it was found that it also plays an essential role in controlling the expression of Yersinia and Salmonella virulence functions (Dorman et al., 1989; Dorrell et al., 1998; Lee et al., 2000; Brzostek et al., 2012). In Yersinia, it is required for serum resistance, survival within macrophages, biofilm formation, and it influences the adhesion/invasion abilities (e.g., invasin, Ail). It was further shown to control expression of the AcrAB-TolC multidrug efflux pump, urease, and a type-VI secretion system (T6SS-4) (Raczkowska et al., 2011a, 2015; Brzostek et al., 2012; Reines et al., 2012; Gueguen et al., 2013; Skorek et al., 2013; Zhang et al., 2013). Recently, it was also demonstrated that OmpR of Yersinia is involved in the control of motility and flagellation by activation of the flagellar operon flhDC (Hu et al., 2009; Raczkowska et al., 2011b). In Salmonella, the EnvZ-OmpR TCS also regulates flagellar and virulence genes, but in this pathogen
OmpR represses $f h D C$ in response to extracellular osmolarity. It has been further implicated in post-transcriptional regulation of the Spi-1-encoded regulator HilD (Ellermeier et al., 2005; Golubeva et al., 2012) and functions as an activator of Spi-2 virulence genes (Lee et al., 2000; see also Regulation of Motility, Attachment and Invasion of the Intestinal Epithelium).

Another virulence-relevant TCS, the BarA/UvrY (SirA) system, is activated by metabolic end products (e.g., short-chain fatty acids such as format, acetate) and an imbalance of the TCA cycle (Takeuchi et al., 2009; Chavez et al., 2010). This signal transduction system is conserved in many $\gamma$-proteobacteria and controls the expression of small regulatory RNAs with unpaired GGA motifs, which are part of the Csr system (Heeb and Haas, 2001; Lapouge et al., 2007). In Yersinia and Salmonella the BarA/UvrY(SirA) system controls the expression of cell invasion genes. It is required for the expression of the Salmonella Spi-1 invasion genes, and transcription of these genes was shown to be restored in a barA mutant by the addition of acetate, but not with butyrate. This indicated that the concentration and composition of short-chain fatty acids in the distal ileum provides a signal for 


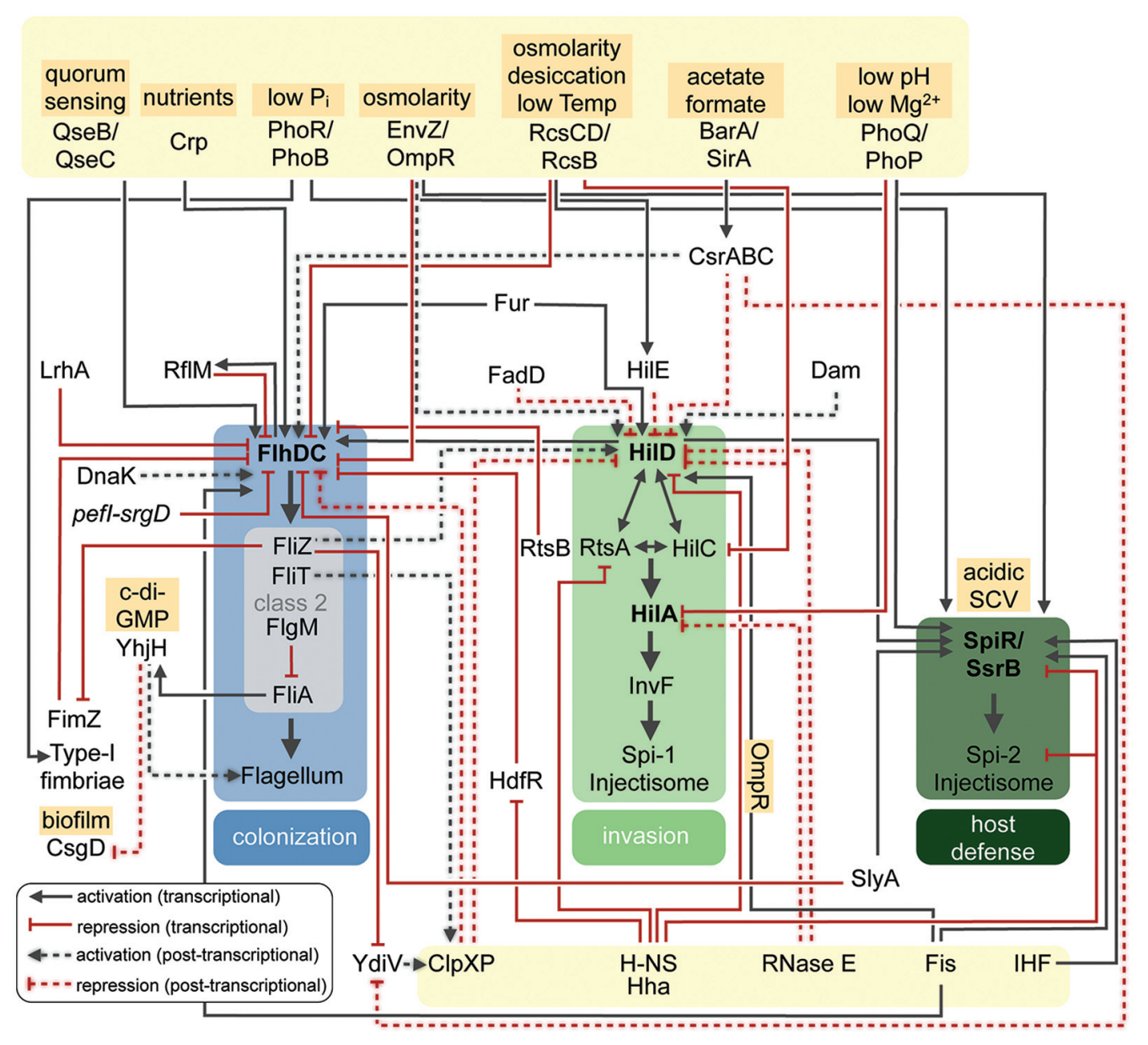

FIGURE 2 | Regulatory networks controlling Salmonella virulence factors. Overview of regulatory and environmental factors that control expression of the major pathogenicity traits of Salmonella needed for host colonization, invasion and host defense. Transcriptional or post-transcriptional regulatory effects are listed.

productive infection by Salmonella (Altier et al., 2000; Lawhon et al., 2002). SirA(UvrY) indirectly activates Spi-1 gene expression by controlling expression and function of Csr-type regulatory RNAs (CsrB, CsrC). CsrB and CsrC inhibit the function of the RNA-binding protein CsrA, which in turn prevents translation of hilD, a major activator of Spi-1 (see also Attachment and Invasion of the Intestinal Epithelium, Figure 2; Altier et al., 2000; Teplitski et al., 2006; Martinez et al., 2011). Similar to Salmonella, BarA/UvrY(SirA) controls expression of the CsrB RNA of Yersinia, which also regulates the expression of host cell adhesion and invasion genes (e.g., invasin), however, through a very different signal transduction cascade (see Attachment and Invasion of the Intestinal Epithelium, Figure 3).

\section{Metabolic Adaptation by Global Regulatory Systems of the Carbon Metabolism}

Several global regulators, which are highly conserved between Salmonella and Yersinia, are known that govern multiple cascades of control elements and complex networks in order to manage metabolic adaptation and coordinate this process with pathogenicity mechanisms. Among them is the cAMP receptor protein Crp. This regulator helps the pathogens to rank available C-sources in order to optimize their metabolism (Gorke and Stulke, 2008; Poncet et al., 2009). Primarily, the bacteria check for the availability of readily digestible sugars such as glucose and fructose. In the absence of these efficiently utilizable sugars, the signal metabolite CAMP is produced by the adenylate cyclase, which then binds to Crp to form an active cAMP-Crp complex (Hanamura and Aiba, 1991; Ishizuka et al., 1994). This metabolic sensor complex was recently shown to control more than $6 \%$ of the genes in Y. pseudotuberculosis (Heroven et al., 2012b; Nuss et al., 2015). crp mutants of Y. pseudotuberculosis and $Y$. enterocolitica are strongly attenuated, and comparative transcriptomics, metabolomics, and phenotypic microarrays showed that Crp is required for growth on different carbon sources and promotes survival under carbon, nitrogen, and phosphate limitation (Petersen and Young, 2002; Heroven et al., 2012b; Nuss et al., 2015). In a recent study using RNA-Seq we could also demonstrate a massive remodeling of the Crp-controlled network in response to temperature and discovered Crp as a transcriptional master regulator of numerous conserved regulatory RNAs, which adjust the Yersinia 


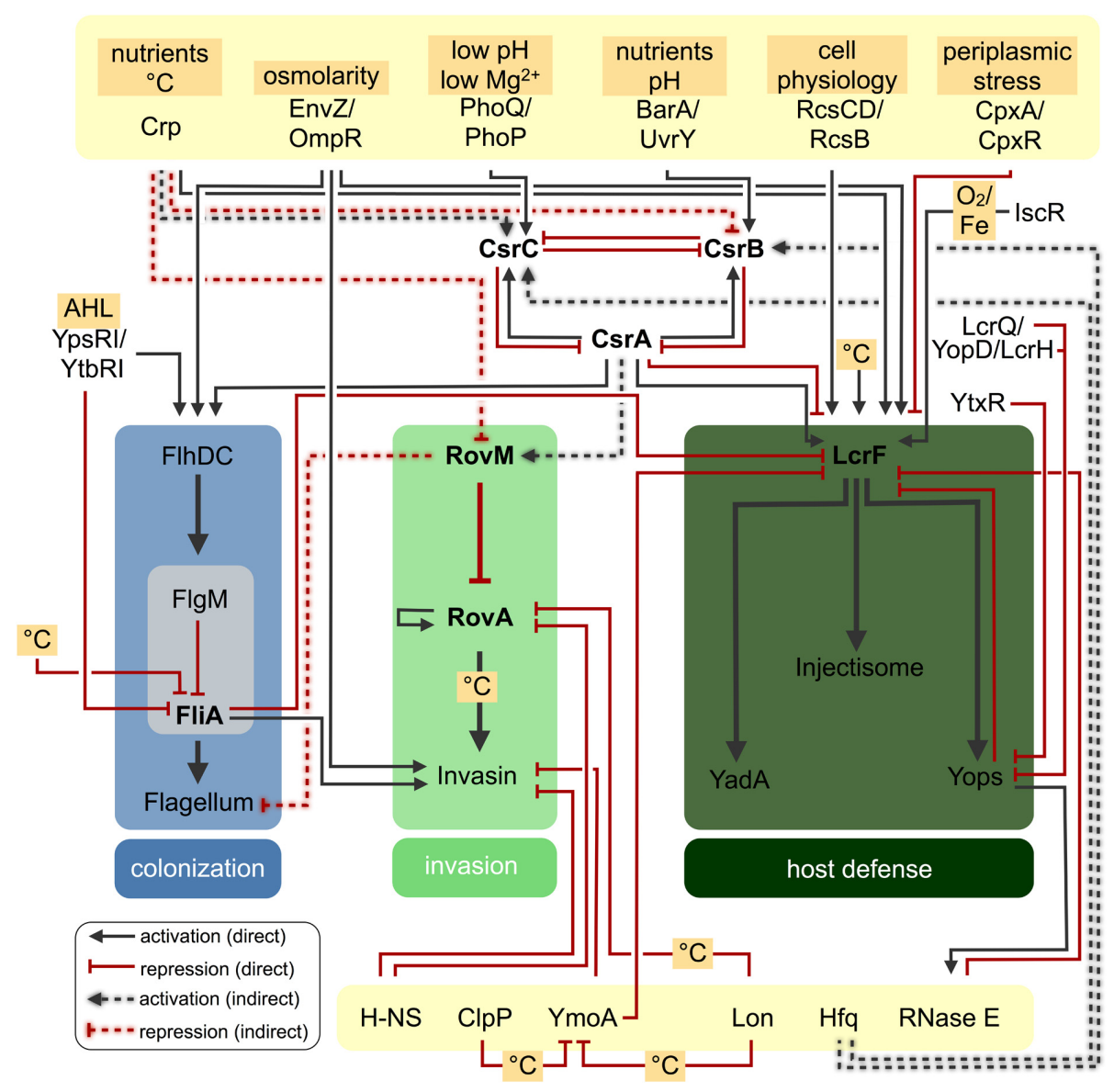

FIGURE 3 | Regulatory networks controlling Yersinia virulence factors. Regulatory networks controlling expression of motility, adhesion and injectisome virulence traits in Yersinia. Direct or indirect regulatory effects of various factors are indicated.

metabolism and fitness to the requirements of their life-style in the intestine (Nuss et al., 2015). Moreover, Crp was found to link nutrient status/carbon metabolism and the regulation of virulence factors, e.g., via the control of the switching of the two Csr-RNAs CsrB and CsrC of Y. pseudotuberculosis (Heroven et al., 2012b). Similarly, Crp of Salmonella enterica serovar Typhimurium was shown to coregulate carbon metabolism and virulence directly and indirectly through the Csr system (see below and Section Attachment and Invasion of the Intestinal Epithelium; Teplitski et al., 2006), indicating that this regulator fulfills a similar role in this enteric pathogen. In fact, a crp mutant of Salmonella is completely attenuated in mice (Zhang et al., 1997).

As mentioned above, the other crucial global metabolic control system of Yersinia and Salmonella, the Csr system, is constituted of the global regulatory RNA-binding protein CsrA and the two antagonizing non-coding sRNAs CsrB and CsrC that bind and sequester multiple CsrA dimers. This prevents CsrA binding to lower affinity mRNA targets, which results in altered mRNA translation and/or stability (Heroven et al., 2012a; Romeo et al., 2012, 2013; Vakulskas et al., 2015). The CsrA protein interacts generally with hairpin structures located in the $5^{\prime}$-untranslated regions of its target genes that possess a GGA motif within the single-stranded loop with conserved flanking regions (RUACARGGA) (Vakulskas et al., 2015). For instance, the binding of a CsrA dimer to one GGA-containing site was shown to allow bridging and binding to another site overlapping the ribosome-binding site of a target gene which resulted in translation repression (Mercante et al., 2009). CsrA has a global influence on the Yersinia transcriptome, and in total approximately $20 \%$ of the CsrA-dependent genes of $Y$. pseudotuberculosis are involved in a myriad of metabolic processes and are controlled in response to ions and availability of carbon sources (Heroven et al., 2012a; Bücker et al., 2014). Similarly, the absence of the csrA gene in Salmonella also greatly reduces mRNA levels of a large number of metabolic genes, e.g., genes for the utilization of maltose, propanediol, and ethanolamine (common carbon sources/nutrients of the intestinal tract), tetrathionate metabolism, and hydrogen sulfide production. Most importantly, these metabolic functions enable Salmonella to use tetrathionate as a terminal electron acceptor in the intestinal tract and allow the microbe to grow on degradation products of the microbiota (Lawhon et al., 2003; Winter et al., 2010). 


\section{Regulation of Motility}

Flagella-mediated motility is used by Salmonella and Yersinia for movement in the intestinal lumen. The chemotactic motility is required for efficient colonization in the intestinal tract, host cell invasion and induction of pathogenesis. It allows the pathogen to benefit from the increased nutrient availability in the inflamed intestine, and initiates host cell contact and invasion (Young et al., 2000; Stecher et al., 2004, 2008). Flagella are rotary motility organelles and rotation of the rigid flagellar filaments provides the pathogens with propulsion forces for chemotactic movement through liquids (swimming) and highly viscous environments or surfaces (swarming) (Chevance and Hughes, 2008). The bacterial flagellum is assembled by a flagellar-specific type-III secretion system (f-T3SS) that is highly homologous to the virulence-associated type-III secretion systems (v-T3SS) of the injectisome devices (Abby and Rocha, 2012). Enteropathogenic yersiniae and S. enterica serovar Typhimurium produce flagella during colonization of the intestinal mucosa, but repress flagella production after invasion of the intestinal epithelial layer. The structural subunits, forming the flagellar filament, are critical because they are potent inducers of the innate immune system of the host (Young et al., 2000; Hayashi et al., 2001). Regulation of flagella production is tightly linked with the expression of the virulence-associated injectisome devices (v-T3SS) employed by many Gram-negative pathogens to manipulate host cells (Iyoda et al., 2001; Horne and Pruss, 2006; Mouslim and Hughes, 2014) (see also Attachment and Invasion of the Intestinal Epithelium).

The correct spatiotemporal assembly of the flagellum is a complex process that involves temporal regulation of more than 60 genes organized into a transcriptional hierarchy of three promoter classes (Kapatral et al., 2004; Chevance and Hughes, 2008; Anderson et al., 2010). The first levels of this hierarchy are similar between Yersinia and Salmonella. On top of the transcriptional regulatory cascade, many environmental stimuli are integrated at the level of the flagellar master regulatory operon, $f h D C$, which is expressed from a $\sigma^{70}$-dependent flagellar Class 1 promoter (Yanagihara et al., 1999; Young et al., 1999; Kapatral et al., 2004). The active $\mathrm{FlhD}_{4} \mathrm{C}_{2}$ heteromultimeric complex (FlhDC) directs $\sigma^{70}$-RNA polymerase (RNAP) to transcribe from flagellar Class 2 promoters (Liu and Matsumura, 1994; Wang et al., 2006), which regulate (i) the expression of the flagellar hook basal body ( $\mathrm{HBB}$ ) complex including the f-T3SS components needed for the export of all subsequent extra-cytoplasmic subunits and (ii) two regulators, the flagellaspecific alternative sigma factor, $\sigma^{28}$ (encoded by fliA) and its cognate anti-sigma factor, FlgM (Iriarte et al., 1995; Liu and Matsumura, 1995; Ding et al., 2009). Transcription from flagellar Class 3 promoters is specific for $\sigma^{28}$-RNAP and occurs only after a functional HBB structure has been assembled (Karlinsey et al., 2000). The binding of FlgM to $\sigma^{28}$ prevents premature $\sigma^{28}$. RNAP-dependent Class 3 transcription and thereby mediates a temporal sensing of the assembly state of the flagellum (Ohnishi et al., 1992; Chadsey et al., 1998). Prior to completion of the HBB structure, the f-T3SS exports only early secretion substrates and does not recognize the late secretion substrate FlgM. Upon HBB completion, the f-T3SS undergoes a switch in secretion specificity and FlgM is recognized as a late secretion substrate and secreted from the cell, thereby allowing for $\sigma^{28}$-dependent transcription from Class 3 promoters (Hughes et al., 1993; Kutsukake, 1994). Gene products transcribed from Class 3 promoters include structural components of the chemotaxis machinery, the filament, and motor-force generators. Overall the hierarchy of flagellar expression is similar in Yersinia. However, several differences include (i) the presence of three tandem flagellin genes (fleA, fleB, fleC) in Y. enterocolitica, (ii) a different set of flagellar genes that are controlled directly by FlhDC and FliA (Class IIIa), and (iii) different expression levels/operon structure of certain flagellar genes, e.g., fliA and fliZ (Horne and Pruss, 2006). Moreover, although a direct interaction of the Y. pseudotuberculosis FlgM protein to $\sigma^{28}$ was confirmed and shown to repress expression of the single flagellin gene $(f l i C)$ in $Y$. pseudotuberculosis, a flgM mutant of $Y$. enterocolitica and $Y$. pseudotuberculosis is non-motile. This suggested that the flagellin genes might be post-transcriptionally regulated (Kapatral et al., 1996; Ding et al., 2009). In addition, other differences exist in the regulatory hierarchies driven by FliA and FlgM when compared to Salmonella, and additional sigma factors apart from $\sigma^{28}$ (e.g., $\sigma^{54}$ ) were found to be involved in the control of flagellar biosynthesis (Ding et al., 2009).

Expression of the flagella is tightly regulated and several layers of autoregulation exist that fine-tune expression of the flagellar system. The regulatory circuits are very well characterized in Salmonella. One regulatory circuit involves autoregulation of flhDC gene transcription. After activation of flagellar synthesis, the FlhDC complex initiates a regulatory feedback loop by activating transcription of its own repressor, RflM (Singer et al., 2013), which provides a mechanism to fine-tune $f h D C$ expression levels. In Salmonella, the Class 2 gene product FliT also has been shown to have a dual function as an f-T3SS secretion chaperone of the filament cap protein FliD and as a regulator of FlhDC activity (Fraser et al., 1999; Yamamoto and Kutsukake, 2006). FliT negatively regulates FlhDC activity by inhibiting promoter binding of the FlhDC complex and increases ClpXP-dependent proteolysis of the FlhC subunit (Yamamoto and Kutsukake, 2006; Sato et al., 2014). Secretion of its cognate secretion substrate FliD after HBB completion releases FliT and thereby provides a mechanism to fine-tune flagellar numbers in response to the growth rate (Aldridge et al., 2010). Although the organization of the flagellar genes in operons and the arrangement along the chromosome differs between Salmonella and enteropathogenic yersiniae, the order and sequence of the flagellar genes, including $f l i T$ and $f l i D$ is mostly conserved (Horne and Pruss, 2006; Ding et al., 2009), suggesting that the overall functions might be maintained.

Another Class 2 gene product, FliZ, is a positive regulator of flagellar Class 2 and Class 3 gene transcription, which increases FlhDC activity by two distinct mechanisms (Kutsukake et al., 1999) (Figure 2). First, FliZ is a transcriptional repressor of the EAL-domain protein YdiV (Wada et al., 2011b). The YdiV protein binds to the FlhD subunit and prevents binding of FlhDC to Class 2 promoters by targeting FlhDC complex to ClpXP-mediated proteolytic degradation (Wozniak et al., 2009; Takaya et al., 2012). Expression of YdiV is high under nutrient starvation in Salmonella and low under high nutrient conditions 
(Wada et al., 2011a). Accordingly, Salmonella is only motile when nutrients are plentiful in contrast to many other bacteria (Wada et al., 2012). The second mechanism by which FliZ activates Class 2 and 3 gene transcription in Salmonella is via positive feedforward regulation of invasion gene expression encoded on Spi-1 (Lucas et al., 2000; Iyoda et al., 2001). FliZ is needed for efficient induction of the Spi-1 system via post-translational activation of the Spi-1 regulatory protein HilD, which in turn activates flhDC gene transcription (Iyoda et al., 2001; Chubiz et al., 2010; Mouslim and Hughes, 2014; Singer et al., 2014).

Although much less is known about the regulatory components implicated in the control of Yersinia motility and flagella formation, a similar close regulatory cross-circuit between the flagellar (f-T3SS) and Yersinia virulence plasmid (pYV)-encoded $\mathrm{v}$-T3SS/injectisome regulons was detected (Figure 3). However, the components implicated in the crosstalk appear to differ significantly. An upregulation of the Yersinia v-T3SS/yop regulon was observed in an flhDC mutant of $Y$. enterocolitica (Bleves et al., 2002). Several groups further reported that certain injectisome genes contain a consensus FliA promoter sequence, and Horne et al. observed a negative effect of the flagellar-specific alternative sigma factor $\sigma^{28}$ on the expression of four injectisome genes (Iriarte et al., 1995; Kapatral et al., 1996; Horne and Pruss, 2006). This regulation seems to be indirect and mediated by the transcriptional master activator LcrF/VirF, which activates transcription of the majority of all v-T3SS and associated yop effector genes (Horne and Pruss, 2006). In addition, FliA was found to induce expression of the primary invasin gene invA, which is encoded between two flagellar operons (Badger and Miller, 1998; Horne and Pruss, 2006). Vice versa, this coregulation ensures coexpression of flagellar-mediated motility and invasin-promoted host cell invasion by enteric yersiniae.

As flagellar synthesis consumes a significant proportion of the cell's biosynthetic capacities a plethora of environmental signals and a myriad of negative and positive control mechanisms are integrated on the level of $f h D C$ gene expression, translation and FlhDC complex stability that ultimately decide the commencement of flagellar biosynthesis. The flhDC promoter of Salmonella displays a complex structure and multiple transcriptional start sites have been identified in recent transcriptome studies (Kröger et al., 2012, 2013). Transcriptional activity of the different promoters in Salmonella depends on the presence of different transcriptional activators such as cAMPCrp, Fur, Fis (P1 promoter), HilD (P5 promoter), and the quorum sensing two-component regulatory system QseBC (Komeda et al., 1976; Yanagihara et al., 1999; Campoy et al., 2002; Kelly et al., 2004; Bearson et al., 2010; Mouslim and Hughes, 2014; Singer et al., 2014). Moreover, flhDC gene expression is also under negative control of the phosphorelay system RcsCDB, the LysR-family protein RflM/EcnR, the Spi-1-encoded regulator RtsB, the LysR-type regulator LrhA (RovM in Yersinia), and SlyA (RovA in Yersinia) with the P1 and P5 promoters being the main regulatory targets (Yanagihara et al., 1999; Wang et al., 2007; Singer et al., 2013; Mouslim and Hughes, 2014). The majority of these regulators is subjected to growth phase control and exerts its control at different stages during the bacterial growth phase. This dynamic separates the transcriptional activation of $f h D C$ into a role for flagellar production during early growth phase from a role in virulence gene expression at later growth phase (Mouslim and Hughes, 2014). Finally, fimbriae-associated genes were also implicated in negative regulation of the $f l h D C$ operon. The pefI and $\operatorname{srg} D$ genes are encoded on the Salmonella virulence plasmid as part of the plasmid-encoded $f$ imbriae (pef) locus and function together in repression of flhDC transcription (Wozniak et al., 2009). Fim $Z$ is an activator of type 1 fimbriae and was shown to represses $f h D C$, as well as Spi-1 genes, which indicates that crosstalk between the flagellar, fimbriae and Spi-1 regulatory systems is of importance during the transition from a motile, planktonic lifestyle to intestinal colonization and persistence (Saini et al., 2010).

Much less is known about the regulation of $f l h D C$ expression in Yersinia, but varying expression levels under different environmental conditions (Nuss et al., 2014) suggest a similar complex regulation pattern. In fact, several transcriptional regulators are already known to influence flagella formation and motility. Analysis of flhDC expression in Y. enterocolitica revealed a role of OmpR/EnvZ in the positive control of the flagellar operon, which is in contrast to the negative role observed in E. coli (Hu et al., 2009). Furthermore, the two hierarchical quorum sensing LuxRI orthologs (YpsRI and YtbRI) of Yersinia control swimming motility via regulation of $f h D C$ and $f l i A$, whereby $N$-acylhomoserine lactones (AHLs) synthesized via YtbI activate $f l h D C$, in conjunction with YpsR, but repress $f l i A$ in conjunction with YtbR and YpsR. A mutant analysis further indicated that quorum sensing regulates motility both positively (via YtbRI) and negatively (via YpsRI) (Atkinson et al., 1999, 2008). A recent study addressing gene regulation by the quorum sensing proteins YenR and YenI of $Y$. enterocolitica further demonstrated that YenR represses expression of yenS, encoding two non-translated RNAs 169 and 105 nucleotides long that share the same $5^{\prime}$ end, which play a stimulatory role in swarming motility (Tsai and Winans, 2011). Similar to Salmonella, the LrhA homolog RovM of Yersinia was found to repress motility by reducing the number of flagella in Y. pseudotuberculosis, whereas the RovM-dependent SlyA homolog RovA had no influence (Heroven and Dersch, 2006).

On the post-transcriptional level, it has been shown that also the carbon storage regulator CsrA is required for motility in both enteropathogenic Yersinia species (Heroven et al., 2008). For Y. pseudotuberculosis it was found that CsrA interacts directly with the $5^{\prime}$-untranslated region of the flhDC mRNA and stimulated FlhDC synthesis most likely by protecting the mRNA from RNase E cleavage similar to what has been observed in E. coli (Heroven et al., 2008). Recently, it has also been shown that CsrA is involved in the activation of the FlhDC/FliA cascade in Salmonella. Regulation of $\mathrm{flhDC}$ expression via CsrA is consistent with reports that the BarA/SirA TCS represses the flagellar regulon indirectly, most likely by regulating $\operatorname{cs} r B$, which in turn is an antagonist of CsrA activity (Teplitski et al., 2003, 2006). In Salmonella, CsrA is known to control the expression of the specific phosphodiesterase YhjH (STM3611), governing the synthesis of $\left(3^{\prime}-5^{\prime}\right)$-cyclicdiguanosine monophosphate (c-di-GMP), which reciprocally 
regulates flagella function and production of biofilm matrix components (Jonas et al., 2010). Furthermore, it has been reported that the BarA/SirA TCS represses the flagellar regulon indirectly, most likely by regulating $\operatorname{csrB}$ (Teplitski et al., 2003, 2006).

Temperature is a key environmental cue for yersiniae, and unlike S. enterica serovar Typhimurium, both enteropathogenic Yersinia species are not motile at $37^{\circ} \mathrm{C}$. Loss of motility at body temperature is due to a rapid repression of the flagellar operons (Kapatral et al., 1996). Temperature-dependent regulation of the flagellar genes appears to occur through $\sigma^{28} / \mathrm{FliA}$, as a rapid reduction of fliA mRNA was observed at a temperatureupshift, whereas the $f h D C$ master operon is transcribed in a temperature-independent manner (Kapatral et al., 2004; Nuss et al., 2015). Notably, in a fliA-deficient mutant, also the temperature-dependent expression levels of all plasmid-encoded v-T3SS/yop genes were considerably reduced (Horne and Pruss, 2006). This indicated that FliA further contributes to temperature regulation of crucial virulence genes, most likely through is influence on $l c r F / v i r F$.

\section{Attachment and Invasion of the Intestinal Epithelium}

Enteric pathogens such as salmonellae and yersiniae are armed with a set of classical virulence factors (e.g., adhesins, invasins) that promote tight attachment of the bacteria to the mucosal surface of the intestinal tract and induce their passage through the intestinal epithelial layer into underlying lymphatic tissues. During the early stages of the infection both enteropathogenic Yersinia species as well as S. enterica serovar Typhimurium bind to and invade into $\mathrm{M}$ cells of the epithelium, overlaying the Peyer's patches in the most distal part of the ileum (Grutzkau et al., 1990; Jones et al., 1994). The surface-exposed outer membrane protein invasin is the most efficient adhesion and internalization factor of enteropathogenic yersiniae (Marra and Isberg, 1997; Grassl et al., 2003; Handley et al., 2005). The invasin protein, which is required for the colonization of the intestinal tract of mice and pigs (Schaake et al., 2013), is in most enteric Yersinia strains predominantly produced at moderate temperature during stationary phase mimicking the free-living or food-associated lifestyle (Isberg et al., 1988; Pepe et al., 1994). This expression pattern seems to guarantee rapid internalization into $M$ cells shortly after ingestion.

The MarR-type regulator RovA, a dimeric winged-helix DNAbinding protein of the SlyA/Hor/Rap family activates invA transcription in response to temperature (Revell and Miller, 2000; Nagel et al., 2001; Heroven et al., 2004). A detailed structurefunctional analysis of RovA revealed that RovA is an intrinsic temperature-sensing protein - a protein thermometer - in which thermally induced conformational changes of a small loop in the dimerization domain (i) interfere with the DNA-binding capacity of the regulator, and (ii) render the regulatory protein more susceptible to proteolytic degradation by the Lon protease (Herbst et al., 2009; Quade et al., 2012; Uliczka and Dersch, 2012). An analysis comparing the invasion properties of $Y$. enterocolitica $\mathrm{O}: 3$ and $\mathrm{O}: 8$ strains revealed that RovA stability is enhanced in Y. enterocolitica O:3 strains due to a P98S substitution in
RovA. Y. enterocolitica O:3 is an emerging pathogen using pigs with a higher body temperature $\left(39-41^{\circ} \mathrm{C}\right)$ as preferred reservoir hosts, and this stabilized RovA variant was found to improve persistence of the pathogen in the porcine intestinal tract (Schaake et al., 2014; Valentin-Weigand et al., 2014). Most interestingly, SlyA, the close homolog of RovA from Salmonella with a very similar structure, is not a thermosensor and remains fully active and stable at $37^{\circ} \mathrm{C}$. Introduction of only three amino acid substitutions, reflecting evolutionary replacements in SlyA, were sufficient to eliminate the thermosensing properties of RovA and prevent degradation (Quade et al., 2012). This indicated that only minor changes can transform a thermotolerant regulator into a thermosensor that allows adjustment of virulence and fitness determinants in response to the temperature of their environment. Strikingly, in contrast to RovA, SlyA is not involved in invasion or the colonization of the small intestine, but it is required for the survival and replication in host phagocytes and destruction of $\mathrm{M}$ cells during later stages of the infection (Libby et al., 1994; Daniels et al., 1996; Buchmeier et al., 1997; Watson et al., 1999; see Regulatory Circuits Controlling Later Stages of Infection and Defense Systems against the Host's Immune Response).

Transcription of rovA and the RovA-regulated $\operatorname{invA}$ gene is also subjected to silencing by the ancestral nucleoid-structuring protein H-NS (Heroven et al., 2004; Ellison and Miller, 2006) (Figure 3), a global regulator implicated in the xenogeneic repression of many virulence and physiological genes acquired by horizontal gene transfer (Navarre et al., 2006; Dorman, 2007). $\mathrm{H}-\mathrm{NS}$ and RovA bind preferentially to AT-rich regions and their binding sites are superimposed in both the invA and rovA regulatory region (Heroven et al., 2004). Active RovA alleviates transcriptional repression by $\mathrm{H}-\mathrm{NS}$ and stimulates the activity of the RNAP (Tran et al., 2005). This antisilencing mechanism seems common in Yersinia, as several other genes have been identified, that are controlled by both regulators (Cathelyn et al., 2007). It is also observed in many other Enterobacteriaceae, including Salmonella, where H-NS promotes silencing of invasion gene regulators encoded on Spi-1, apparently to buffer fitness costs that were associated with acquisition and expression of host colonization factors (Olekhnovich and Kadner, 2007).

$\mathrm{H}-\mathrm{NS}$ is also capable to form heterodimers with members of the Hha/YmoA family. Hha and YmoA are small basic proteins that have been shown to participate in the modulation of virulence gene regulation in different Gram-negative bacteria (Madrid et al., 2006; Stoebel et al., 2008). Formation of YmoAH-NS complexes has been shown to modulate expression of invasion and several other H-NS-dependent virulence genes in Yersinia (Ellison et al., 2003; Heroven et al., 2007) and in Salmonella. However, the molecular mechanism how YmoA/Hha modulates H-NS is not well understood since its influence varies considerably among the H-NS-dependent genes in the different microorganisms. Nonetheless, it is evident that the global influence of H-NS enables the pathogens to link this set of virulence-relevant genes with other environmental control systems. For instance, the H-NS modulator YmoA is preferentially degraded at $37^{\circ} \mathrm{C}$ by the $\mathrm{ClpP}$ and Lon proteases 
in Yersinia (Jackson et al., 2004), and in Salmonella it has been shown that transcription of the hns gene - which influences expression of the Spi-1-encoded invasion genes through the regulator HilD - is repressed by the iron homeostasis regulator Fur (Troxell et al., 2011). Metal-bound Fur has also been shown to bind to an AT-rich region of the hilD promoter to stimulate hilD transcription (Ellermeier and Slauch, 2008; Teixido et al., 2011).

The LysR-type regulator RovM (LrhA in Salmonella) was identified as another repressor of rovA expression, and full repression of rovA expression can only occur through the cooperation of RovM with H-NS (Heroven and Dersch, 2006). RovM synthesis is only activated under nutrient limiting conditions, and this strongly suggested that dependency of rovA and invA expression on the availability of nutrients is mainly mediated through RovM (Heroven et al., 2007). In fact, later attempts to unravel the molecular regulatory mechanism of rov $M$ revealed that the nutrient and ion-controlled Csr system is responsible for rovM expression in response to the supply of carbon sources of the growth media (Heroven et al., 2008) (Figure 3). Overexpression of UvrY, CsrB, and CsrC resulted in a strong decrease of RovM levels and an increase of rovA transcription, and high amounts of the RovA protein can be detected in a $\operatorname{csr} A$ mutant in minimal media in which rovA expression is normally fully repressed (Heroven et al., 2008; Bücker et al., 2014). A detailed expression analysis further revealed that in contrast to the Salmonella Csr system, both CsrB and CsrC are counter-regulated and respond to different TCS in response to metabolites (UvrY/BarA-CsrB) or ions (PhoP/PhoQ-CsrC) and are oppositely controlled by the Crp protein (Heroven et al., 2008; Nuss et al., 2014). Apart of its influence on the RovM-RovA-InvA regulatory cascade, the Yersinia Csr system and Crp are part of a large adaptive response network, adjusting metabolic, and physiological processes, stress adaptation and virulence gene expression in response to changing environmental conditions (Heroven et al., 2012a; LeGrand et al., 2015; Nuss et al., 2015; Vakulskas et al., 2015). A recent study elucidated a tight connection between pathogenicity and core metabolism by integrated transcriptome and ${ }^{13} \mathrm{C}$-fluxome analysis of $Y$. pseudotuberculosis, and identified the pyruvateTCA cycle node as a focal point for controlling the host colonization and virulence of Yersinia which is tightly controlled by the interplay of Crp and the Csr system (Bücker et al., 2014).

In contrast to Yersinia, initial invasion and transcytosis of Salmonella through the intestinal layer requires the expression of the Spi-1-encoded injectisome system, which is controlled by a very distinct regulatory cascade (Figure 2). The appropriate environmental conditions to allow invasion are sensed by a myriad of regulators encoded both inside and outside of the pathogenicity island (PAI). A key regulator of Spi-1 is the OmpR/ToxR family protein HilA, and all environmental signals that sense optimal conditions for Spi-1 expression are integrated on the level of HilA expression (Bajaj et al., 1996; Ellermeier and Slauch, 2007). HilA is a positive regulator that primarily activates transcription of genes encoding structural components of the Spi-1 injectisome system, including the prg/org and inv/spa operons (Lee et al., 1992; Bajaj et al., 1995) and other virulence genes outside Spi-1, including the Spi-4 encoded sii operon
(Gerlach et al., 2007). hilA gene transcription is controlled by a complex feed-forward loop comprised of the three AraC-like regulatory proteins HilC, HilD, and RtsA encoded on Spi-1 or on a separate $15 \mathrm{~kb}$ island (Schechter and Lee, 2001; Ellermeier and Slauch, 2003; Ellermeier et al., 2005) (Figure 2). Each of the three regulators can independently bind and activate the hilA promoter, their own gene, and the genes of the respective other regulators by counteracting silencing mediated by $\mathrm{H}-\mathrm{NS}$ and Hha (YmoA in Yersinia) (Olekhnovich and Kadner, 2002; Ellermeier et al., 2005; Olekhnovich and Kadner, 2006). It has been proposed that the feed-forward loop system of HilC, HilD, and RtsA functions as a switch that controls hilA expression by modulating the threshold of HilD protein required for the ultimate HilA activation. In this context, HilD is the key activator of hilA transcription and various environmental signals are known to influence HilD production and activity, whereby RtsA and HilC function as amplifiers of the activating signal (Ellermeier and Slauch, 2007). Moreover, HilD coordinates hilA transcription with the expression of other crucial infection-relevant systems, e.g., it induces expression of the flagellar operons through activation of $f h D C$ transcription and controls expression of Spi-2 genes (see also the Sections Regulation of Motility and Regulatory Circuits Controlling Later Stages of Infection and Defense Systems against the Host's Immune Response).

The temporal coordination of flagellar and Spi-1 gene expression plays an important role during the initial phase of the Salmonella infection cycle when the bacteria are initially motile in the lumen and subsequently turn on Spi-1 virulence genes needed for invasion of the epithelial layer. This is achieved by the flagellar-encoded regulator FliZ, which simultaneously represses type 1 fimbriae and activates Spi-1 via HilD (Iyoda et al., 2001; Chubiz et al., 2010). In the following stages flagellar gene expression is downregulated on the level of the $f l h D C$ promoter by the combined action of multiple regulators, including the Spi-1-dependent RtsB protein and the type 1 fimbriae regulator FimZ (Ellermeier and Slauch, 2003; Saini et al., 2010; Mouslim and Hughes, 2014; Singer et al., 2014). At later stages of the infection, synthesis of Spi-1 stops and expression type 1 fimbriae is upregulated (Saini et al., 2010). It is presumed that the expression of adhesive structures is needed for colonization and persistence of bacteria that were unable to breach the intestinal epithelium during the initial infection (Saini et al., 2010).

Based on the importance of HilA and HilD for Spi-1 gene expression, it is not surprising that various regulatory factors control their synthesis and activity in response to environmental conditions and ion/nutrient availability (Figure 2). Among them are the Salmonella-specific negative regulator HilE, which interacts with HilD and affects its activity, and multiple conserved regulatory factors: (i) the acyl-CoA synthetase FadD, (ii) the EnvZ/OmpR, PhoP/PhoQ and the Rcs phosphorelay systems controlling hilD or hilA transcription (Bajaj et al., 1995; Pegues et al., 1995; Garcia-Calderon et al., 2007), (iii) the DNA adenine methylase Dam and the degradosome (RNaseE), which regulates hilA and/or hilD mRNA stability and translation (Fahlen et al., 2000; Boddicker et al., 2003; Lopez-Garrido et al., 2014), (iv) the Lon and ClpXP protease (Kage et al., 2008), and (v) the BarA/SirA-CsrABC signal cascade in which CsrA negatively 
affects hilD translation by binding the ribosome-binding site of the hilD mRNA (Baxter et al., 2003; Ellermeier et al., 2005; Chubiz et al., 2010; Martinez et al., 2011). Apart from H-NS and Hha the factor for inversion stimulation (Fis), also controls Spi-1 gene expression. Fis-mediated activation of the Spi-1 genes occurs through different regulatory modes: Fis binds to promoters of Spi-1 encoded genes, or controls conserved upstream regulators such as OmpR to influence the Spi-1 regulator HilD. Fis binds preferentially to supercoiled DNA, and Fis-promoted activation coincides with a high level of nucleoid supercoiling under anaerobic conditions in the gut during the initial infection of Salmonella (Wilson et al., 2001; Wang et al., 2013).

\section{Regulatory Circuits Controlling Later Stages of Infection and Defense Systems against the Host's Immune Response}

Efficient dissemination and long-term persistence of S. enterica serovar Typhimurium and both enteric Yersinia species in deeper tissues require the expression of an additional set of virulence genes, which allow them to resist host immune responses. The most important defense system of yersiniae is encoded on the virulence plasmid pYV. It includes the yadA adhesin gene, the $y s c$ genes encoding a v-T3SS/injectisome and its dedicated yop effector genes (Cornelis et al., 1998), which are important to survive and multiply in the lymphoid tissues of their host. This integrated defense system prevents uptake and elimination of the extracellular pathogens by professional phagocytes. It disarms their phagocytic function, disrupts their communications, and induces their apoptosis by the injection of the Yop effector proteins which interfere with the cytoskeletal structure and certain signal transduction pathways (Bliska et al., 2013). All these virulence genes belong to the same regulon and their transcription is activated by the AraC-type regulator $\mathrm{LcrF}(\mathrm{VirF})$ in response to temperature and host cell contact (Bolin et al., 1988; Pettersson et al., 1996). A subset of the genes is also regulated by the presence of $\mathrm{Ca}^{2+}$, a phenomenon, which is referred to as low calcium response (LCR) (Goguen et al., 1984; Straley et al., 1993). ysc/yop genes were also found to be regulated by proteins that antagonize $\mathrm{LcrF}(\mathrm{VirF})$. One example is YtxR which competes with $\mathrm{LcrF}(\mathrm{VirF})$ for binding to the yopE and yopH promoters (Axler-Diperte et al., 2006). Another regulator is LcrQ (YscM1 and YscM2 in Y. enterocolitica), a factor, which is implicated in a feedback circuit that represses ysc-yop gene expression when Yop secretion is inhibited, e.g., in the absence of host cell contact. LcrQ(YscM1/YscM2) in cooperation with the YopD-LcrH complex interacts with $5^{\prime}$ UTRs of multiple ysc/yop mRNAs to block translation. Upon host cell contact LcrQ(YscM1/YscM2) is secreted by the Ysc/Yop $\mathrm{v}$-T3SS machinery, repression is relieved due to lower LcrQ concentration in the cytoplasm and results in the upregulation of the yop and ysc genes (Stainier et al., 1997; Anderson et al., 2002; Chen and Anderson, 2011; Kopaskie et al., 2013).

Thermal control of the Ysc/Yop regulon is mediated through regulation of $l c r F(v i r F)$ and this involves repression of $\mathrm{LcrF}(\mathrm{VirF})$ synthesis by the thermosensitive modulator YmoA and an RNA thermometer. The YmoA-H-NS complex was shown to repress $l c r F$ transcription at moderate temperatures, but this repression is eliminated at $37^{\circ} \mathrm{C}$ due to rapid degradation of the YmoA protein by the Lon and ClpP proteases (Jackson et al., 2004; Heroven et al., 2007; Böhme et al., 2012). Most likely, this derepression is supported by thermally induced changes of the pYV DNA topology (Cornelis et al., 1989; Michiels et al., 1991; Rohde et al., 1994, 1999). Furthermore, it has been demonstrated that the $5^{\prime}$-UTR of the $\operatorname{lcr} F(v i r F)$ mRNA forms a temperature-sensitive two-stem-loop structure (RNA thermometer) at moderate temperatures in which the ShineDalgarno sequence is sequestered in the stem of the second hairpin and prevents $l c r F$ mRNA translation (Hoe and Goguen, 1993; Böhme et al., 2012). However, an upshift to $37^{\circ} \mathrm{C}$ within the host leads to partial denaturation, and opening of the structure allows efficient ribosome binding and $l c r F$ mRNA translation (Böhme et al., 2012). Besides temperature, $\operatorname{LcrF}($ VirF) is also affected by other environmental signals. A genetic screen led to the identification of the transcriptional regulator IscR, which modulates gene transcription depending on the coordination of its $2 \mathrm{Fe}-2 \mathrm{~S}$ clusters which can be influenced by oxidative stress, oxygen limitation, or iron availability (Miller et al., 2014). Similar to the Salmonella v-T3SS regulator HilD, LcrF expression seems also under control of several conserved TCSs: (i) the Rcs phosphorelay which is used to adapt their cell physiology in response to perturbations of the cell envelope (Li et al., 2015), (ii) the BarA/UvrY(SirA) controlling the Csr system in response to carbon sources (LeGrand et al., 2015), and (iii) the CpxAR system that responds to extra-cytoplasmatic stress (Liu et al., 2012). As mentioned above (see Regulation of Motility), LcrF synthesis is also under negative control of the flagellar sigma factor FliA $/ \sigma^{28}$, and this inverse regulation of flagellar and v-T3SS genes ensures that expression of the immune defense apparatus is repressed when Yersinia uses flagellar motility to colonize external habits at temperatures below $30^{\circ} \mathrm{C}$ (Horne and Pruss, 2006).

In contrast to yersiniae, which persist and replicate predominantly extracellularly in lymphatic tissues, salmonellae can actively invade, survive and proliferate efficiently within so-called Salmonella-containing vacuoles (SCVs) inside the eukaryotic cytoplasm (Figure 1). The establishment and integrity of the SCV membrane is ensured by the action of effectors translocated via another horizontally acquired injectisome device encoded on Spi-2. Expression of Spi-2 and downregulation of Spi-1 gene expression marks an important transition from the invasion mode to the intracellular survival stage that is crucially dependent on the correct spatiotemporal action of a variety of activators and repressors of gene expression. The main regulatory proteins involved in the expression of Spi-2 include the two-component systems SpiR(SsrA)/SsrB, PhoP/PhoQ, OmpR/EnvZ, as well as the DNA-binding proteins HilD, SlyA (RovA in Yersinia), RcsB, the iron regulator Fur, and the nucleoid-associated proteins $\mathrm{H}-\mathrm{NS}$, Hha (YmoA in Yersinia), YdgT, IHF, and Fis (Fass and Groisman, 2009; Choi et al., 2014). The membrane-embedded Salmonella-specific sensor kinase SpiR(SsrA) and the response regulator SsrB are the primary activators essential for Spi-2 expression (Walthers et al., 2007), which is induced within the acidic environment of the SCV (Miao et al., 2002; Mulder et al., 2015). SsrB binds to promoter regions of all Spi-2-encoded gene clusters and 
counteracts H-NS-mediated silencing (Walthers et al., 2007). SsrB was also recently shown to downregulate the production of flagellar components in SCVs in macrophages (Brown et al., 2014), which would diminish flagellin-dependent stimulation of the NLRC4 inflammasome (Franchi et al., 2006; Miao et al., 2006). In addition to SsrB, also the SlyA protein (an ortholog of RovA of Yersinia) is implicated in the activation of several Spi-2 genes, mostly to overcome H-NS-mediated silencing (Okada et al., 2007). In contrast to RovA, SlyA does not function as a thermosensor and acts as a negative regulator of flagellar genes at $37^{\circ} \mathrm{C}$ via repression of $f h D C$ (Quade et al., 2012; Mouslim and Hughes, 2014). In addition, two other homologous nucleoidassociated proteins, YdgT and Hha (YmoA in Yersinia) which form heterocomplexes with H-NS prevent Spi-2 gene expression and appear to be important in particular when the bacteria are extracellular (Coombes et al., 2005; Silphaduang et al., 2007).

Similar to the injectisome machinery of Yersinia, expression of the Spi-2 encoded injectisome genes of Salmonella seems to depend on the DNA topology and nucleoid-associated factors that modulate the transcription of the genes by the introduction of conformational changes. One of the modulators, the global DNA-bending protein integration host $f$ actor (IHF) is required for the expression of motility, Spi-1 and Spi-2 genes during the transition from exponential to stationary growth (Mangan et al., 2006). Also Fis, which also promotes Spi-1 gene expression (see Attachment and Invasion of the Intestinal Epithelium), is needed for full expression of Spi-2. Fis binds directly to the promoter regions of spiR and ssaG (Kelly et al., 2004; Lim et al., 2006) and its expression correlates with Spi-2 gene expression inside macrophages (O Croinin et al., 2006). Oxidative stress sensed during later intracellular infection stages results in relaxation of the nucleoid, which activates expression from Spi-2 promoters. Fis seem to accelerate relaxation and stabilizes the promoter topology of $s s r A B$ to allow timely expression of Spi-2 genes (O Croinin et al., 2006; Dillon and Dorman, 2010).

Spi-2 is also controlled by several TCSs that are also implicated in the control of the colonization and invasion factors. Spi-2 genes are activated by the PhoP/PhoQ system that is essential for virulence and survival within macrophages (Miller et al., 1989). The response regulator PhoP controls Spi-2 by binding to the $s s r B$ promoter region and the $5^{\prime}$-UTR of the spiR transcript (Bijlsma and Groisman, 2005). The OmpR/EnvZ two-component system also functions as an activator of Spi-2 by direct binding to both promoter regions of the spiR/ssrB system (Lee et al., 2000; Feng et al., 2003). The phosphorelay system RcsCDB has been shown to have a dual regulatory role as repressor of flagellar $(f l h D C)$ gene expression and activator of Spi-2 expression (Wang et al., 2007).

Expression of the Spi-2 genes is further tightly coordinated with expression of the Spi-1 genes. Cross-talk between the different PAIs is mainly mediated by the Spi-1-encoded regulator protein HilD. HilD antagonizes silencing via H-NS of both, the hilA and spiR promoters, but significantly higher levels of HilD protein are required for $s p i R$ promoter binding. This may explain why HilD regulates Spi-1 and Spi-2 differentially (Bustamante et al., 2008). While the physiological role of the HilD-mediated cross-talk between Spi-1 and Spi-2 remains to be further analyzed in vivo inside host cells, it has been proposed that coordinated regulation of Spi-1 and Spi-2 gene expression involves also IHF (as described above) which influences HilD expression (Fass and Groisman, 2009).

\section{Conclusion and Outlook}

Crucial to the Yersinia and Salmonella's capability to cause a successful infection is their ability to coordinate the expression of a plethora of virulence genes with numerous metabolic and stress adaptation functions required for survival in the different tissues during the course of the infection. To optimize their biological fitness, which is essential to compete with the intestinal microbiota and defend detrimental host responses, they only synthesize pathogenicity factors when they are needed. The importance of the physiological control of virulence-relevant determinants is supported by the fact that their constitutive or deregulated expression can strongly attenuate virulence. In order to govern environmental changes, host stresses and competition, the pathogens generally employ signal transduction systems that sense and respond to particular environmental parameters and host signals by modifying the level and/or activity of transcriptional networks and post-transcriptional control systems including regulatory RNAs, modulator proteins and signal molecules to fine-tune the expression of pathogenicity factors.

Pathogenicity genes are often organized in clusters or large genomic islands on the chromosome or on plasmids which were acquired via horizontal gene transfer. The genetic linkage of the determinants on these so-called PAIs allows the bacteria to coordinately control a set of functionally related virulence factors within a complex regulatory network. Most frequently the virulence operons of the PAIs are under direct control of pathogen-specific transcriptional master regulators (mostly of the AraC family), which are encoded on the PAI (e.g., HilA, HilD in Salmonella, LcrF in Yersinia). In addition to expression of the PAI-encoded genes, also loci outside the PAI can be controlled by the PAI master regulators (e.g., HilD controls flagellar and Spi-2 gene expression). This superimposed control and cross-talk between the different virulence systems enables the pathogens to coordinate the dynamic and order of virulence gene expression in response to the conditions imposed on the pathogen by the colonized host niches. The environmental conditions include availability of carbon/energy sources, oxygen, growth phase, $\mathrm{pH}$, and osmolarity and are transmitted to the regulatory network via ancestral global TCS (e.g., EnvZ/OmpR, PhoP/PhoQ, and BarA/UvrY(SirA). In addition, global regulatory proteins/systems such as Crp, CsrABC, SlyA(RovA), and LrhA(RovM), which adjust virulence gene expression with stress responses, physiological features (biofilm formation/motility) and crucial metabolic functions are included into this network. Another important conserved regulatory feature is the silencing of pathogenicity gene clusters by the nucleoid-associated protein $\mathrm{H}-\mathrm{NS}$ due to its binding preference to DNA with a higher \%AT content. H-NS promoted silencing prevents unwanted virulence gene expression under non-infection conditions (i.e., in environmental niches) to avoid 
fitness loss. This effect can be counter-balanced and modulated by other H-NS-like proteins such as $\mathrm{Hha}(\mathrm{YmoA})$ which modify $\mathrm{H}-\mathrm{NS}$ promoted silencing by heterocomplex formation under certain growth conditions. Furthermore, other DNA-bending modulators such as IHF and Fis counteract H-NS repression and support virulence gene activation by the virulence cluster/PAIspecific activator proteins.

Many of the contributing TCSs, global regulators and regulatory systems, and gene silencer/modulator proteins are conserved between Yersinia, Salmonella and many other Enterobacteriaceae. However, their interactions, arrangement within the complex regulatory network and composition of the control elements vary between the related bacteria. In fact, small variations of the content and organization of the genetic information of the pathogens over time, e.g., point mutations, gene rearrangements, deletions, and insertion of foreign DNA can lead to rapid and fundamental changes. These genetic modifications are the primary forces, which bring out phenotypic differences leading to (i) distinct pathogenic properties and evolution of distinct species, and (ii) adaptation to different environments and alterations of their life-style. In fact, results from our previous work clearly demonstrated that even very small variations provoke major differences in the virulence properties of related pathogens. For instance, a 20 bp insertion can transfer the Yersinia adhesin YadA into an invasin (Heise and Dersch, 2006). Moreover, only three amino acid substitutions can switch the thermotolerant regulatory protein SlyA of Salmonella into a protein thermometer similar to the orthologous Yersinia regulator RovA (Quade et al., 2012). Variations found between the Salmonella Hha and the Yersinia YmoA protein render YmoA but not Hha susceptible to proteases at $37^{\circ} \mathrm{C}$ (Jackson et al., 2004), and a 2 nt exchange can modify a $5^{\prime}$-UTR into an RNA-thermometer (Steinmann and Dersch, 2013). These alterations of crucial control elements can switch thermotolerant gene regulatory circuits into a thermo-responsive control system, which allows pathogens such as Yersinia to inhabit a wide range of environmental, insect-vector- and mammalian host-associated niches.

Another benefit of the complex arrangement of the different regulatory factors is that some regulatory circuits enable heterogenous/bistable expression of certain virulence genes. As a result, a genetically identical bacterial population can consist of subpopulations that express (ON state) or do not express (OFF state) certain virulence factors. This socalled phenotypic heterogeneity can confer clonal subsets of pathogens with different virulence properties, metabolic functions, and/or physiological features. Recent work by Davis et al. (2015) has identified three subpopulations of $Y$. pseudotuberculosis within microcolonies at a single tissue site. The most peripherally localized bacteria which contact

\section{References}

Abby, S. S., and Rocha, E. P. (2012). The non-flagellar type III secretion system evolved from the bacterial flagellum and diversified into hostcell adapted systems. PLoS Genet. 8:e1002983. doi: 10.1371/journal.pgen.100 2983 neutrophils express anti-phagocytic virulence factors, e.g., YopE, the bacteria growing on the exterior of the microcolony induce the nitric oxide (NO)-detoxifying gene hmp and prevents NO diffusion and elimination of the interior bacterial population and illustrates a sophisticated form of division of labor during infection (Davis et al., 2015). Another paradigmatic example of cooperative virulence is the bistable expression of the Salmonella Spi-1 injectisome and flagellar genes. This results in the generation of one subpopulation that expresses Spi-1 genes. A fraction of theses cells invade the intestinal epithelium and induce inflammation, whereas other motile subpopulations consume host products released during inflammation, This enables Salmonella to outcompete the intestinal microbiota and establish a productive infection in a cooperative manner (Ackermann et al., 2008; Diard et al., 2013). The invasive subpopulation is also characterized by a lower growth rate, which is associated with tolerance to certain stresses including the exposure to antibiotics (Diard et al., 2013). This property is referred to as bet-hedging; one subpopulation expresses features optimized for the present environment allowing it to survive and proliferate, whereas another part of the population expresses a phenotype less well adapted to the momentary niche, but adjusted to a state the environment might turn into. This behavior allows a population to survive in an unpredictable and frequently fluctuating environment, as experienced by the pathogen during the different stages of an infection. Future research addressing virulence gene expression in different tissues throughout the infection will elucidate whether phenotypic heterogeneity is restricted to special regulatory circuits or a more general control scheme. Existence of pathogen subsets cannot only hamper the control of infection by certain antibiotic therapies, but it can result in the failure of novel anti-virulence strategies directed against crucial virulence traits, e.g., T3SSs to combat bacterial diseases. An attractive alternative in this context would be the development of anti-virulence strategies directed against major global virulence regulators, which are essential for virulence as they coordinate multiple virulence traits with crucial metabolic and physiological functions of the pathogen.

\section{Acknowledgments}

Our work mentioned in the review was funded by support from the DFG Priority Program SPP1316 (DE/5-2), SPP1617 (DE616/6). PD is supported by the German Centre for Infection Research (DZIF). ME acknowledges funding from the Helmholtz Association young investigator grant VH-NG-932, and the People Programme (Marie Curie Actions) of the European Union Seventh Framework Programme (grant 334030).

Abu Kwaik, Y., and Bumann, D. (2013). Microbial quest for food in vivo: 'nutritional virulence' as an emerging paradigm. Cell. Microbiol. 15, 882-890. doi: $10.1111 / \mathrm{cmi} .12138$

Ackermann, M., Stecher, B., Freed, N. E., Songhet, P., Hardt, W. D., and Doebeli, M. (2008). Self-destructive cooperation mediated by phenotypic noise. Nature 454, 987-990. doi: 10.1038/nature07067 
Aldridge, C., Poonchareon, K., Saini, S., Ewen, T., Soloyva, A., Rao, C. V., et al. (2010). The interaction dynamics of a negative feedback loop regulates flagellar number in Salmonella enterica serovar Typhimurium. Mol. Microbiol. 78, 1416-1430. doi: 10.1111/j.1365-2958.2010.07415.x

Altier, C., Suyemoto, M., Ruiz, A. I., Burnham, K. D., and Maurer, R. (2000). Characterization of two novel regulatory genes affecting Salmonella invasion gene expression. Mol. Microbiol. 35, 635-646. doi: 10.1046/j.13652958.2000.01734.x

Anderson, D. M., Ramamurthi, K. S., Tam, C., and Schneewind, O. (2002). YopD and LcrH regulate expression of Yersinia enterocolitica YopQ by a posttranscriptional mechanism and bind to yopQ RNA. J. Bacteriol. 184, 1287-1295. doi: 10.1128/JB.184.5.1287-1295.2002

Anderson, J. K., Smith, T. G., and Hoover, T. R. (2010). Sense and sensibility: flagellum-mediated gene regulation. Trends Microbiol. 18, 30-37. doi: 10.1016/j.tim.2009.11.001

Atkinson, S., Chang, C. Y., Patrick, H. L., Buckley, C. M., Wang, Y., Sockett, R. E., et al. (2008). Functional interplay between the Yersinia pseudotuberculosis YpsRI and YtbRI quorum sensing systems modulates swimming motility by controlling expression of flhDC and fliA. Mol. Microbiol. 69, 137-151. doi: 10.1111/j.1365-2958.2008.06268.x

Atkinson, S., Throup, J. P., Stewart, G. S., and Williams, P. (1999). A hierarchical quorum-sensing system in Yersinia pseudotuberculosis is involved in the regulation of motility and clumping. Mol. Microbiol. 33, 1267-1277. doi: 10.1046/j.1365-2958.1999.01578.x

Autenrieth, I. B., and Firsching, R. (1996). Penetration of M cells and destruction of Peyer's patches by Yersinia enterocolitica: an ultrastructural and histological study. J. Med. Microbiol. 44, 285-294. doi: 10.1099/00222615-44-4-285

Axler-Diperte, G. L., Miller, V. L., and Darwin, A. J. (2006). YtxR, a conserved LysR-like regulator that induces expression of genes encoding a putative ADPribosyltransferase toxin homologue in Yersinia enterocolitica. J. Bacteriol. 188, 8033-8043. doi: 10.1128/JB.01159-06

Badger, J. L., and Miller, V. L. (1998). Expression of invasin and motility are coordinately regulated in Yersinia enterocolitica. J. Bacteriol. 180, 793-800.

Bajaj, V., Hwang, C., and Lee, C. A. (1995). hilA is a novel ompR/toxR family member that activates the expression of Salmonella typhimurium invasion genes. Mol. Microbiol. 18, 715-727. doi: 10.1111/j.13652958.1995.mmi_18040715.x

Bajaj, V., Lucas, R. L., Hwang, C., and Lee, C. A. (1996). Co-ordinate regulation of Salmonella typhimurium invasion genes by environmental and regulatory factors is mediated by control of hilA expression. Mol. Microbiol. 22, 703-714. doi: 10.1046/j.1365-2958.1996.d01-1718.x

Baxter, M. A., Fahlen, T. F., Wilson, R. L., and Jones, B. D. (2003). HilE interacts with HilD and negatively regulates hilA transcription and expression of the Salmonella enterica serovar Typhimurium invasive phenotype. Infect. Immun. 71, 1295-1305. doi: 10.1128/IAI.71.3.1295-1305.2003

Bearson, B. L., Bearson, S. M., Lee, I. S., and Brunelle, B. W. (2010). The Salmonella enterica serovar Typhimurium QseB response regulator negatively regulates bacterial motility and swine colonization in the absence of the QseC sensor kinase. Microb. Pathog. 48, 214-219. doi: 10.1016/j.micpath.2010.03.005

Belden, W. J., and Miller, S. I. (1994). Further characterization of the PhoP regulon: identification of new PhoP-activated virulence loci. Infect. Immun. 62, 5095-5101.

Bijlsma, J. J., and Groisman, E. A. (2005). The PhoP/PhoQ system controls the intramacrophage type three secretion system of Salmonella enterica. Mol. Microbiol. 57, 85-96. doi: 10.1111/j.1365-2958.2005.04668.x

Bleves, S., Marenne, M. N., Detry, G., and Cornelis, G. R. (2002). Up-regulation of the Yersinia enterocolitica yop regulon by deletion of the flagellum master operon flhDC. J. Bacteriol. 184, 3214-3223. doi: 10.1128/JB.184.12.32143223.2002

Bliska, J. B., Wang, X., Viboud, G. I., and Brodsky, I. E. (2013). Modulation of innate immune responses by Yersinia type III secretion system translocators and effectors. Cell. Microbiol. 15, 1622-1631. doi: 10.1111/cmi.12164

Boddicker, J. D., Knosp, B. M., and Jones, B. D. (2003). Transcription of the Salmonella invasion gene activator, hilA, requires HilD activation in the absence of negative regulators. J. Bacteriol. 185, 525-533. doi: 10.1128/JB.185.2.525533.2003

Böhme, K., Steinmann, R., Kortmann, J., Seekircher, S., Heroven, A. K., Berger, E., et al. (2012). Concerted actions of a thermo-labile regulator and a unique intergenic RNA thermosensor control Yersinia virulence. PLoS Pathog. 8:e1002518. doi: 10.1371/journal.ppat.1002518

Bolin, I., Forsberg, A., Norlander, L., Skurnik, M., and Wolf-Watz, H. (1988). Identification and mapping of the temperature-inducible, plasmid-encoded proteins of Yersinia spp. Infect. Immun. 56, 343-348.

Bottone, E. J. (1999). Yersinia enterocolitica: overview and epidemiologic correlates. Microbes Infect. 1, 323-333. doi: 10.1016/S1286-4579(99)80028-8

Bozue, J., Mou, S., Moody, K. L., Cote, C. K., Trevino, S., Fritz, D., et al. (2011). The role of the phoPQ operon in the pathogenesis of the fully virulent CO92 strain of Yersinia pestis and the IP32953 strain of Yersinia pseudotuberculosis. Microb. Pathog. 50, 314-321. doi: 10.1016/j.micpath.2011.02.005

Brown, N. F., Rogers, L. D., Sanderson, K. L., Gouw, J. W., Hartland, E. L., and Foster, L. J. (2014). A horizontally acquired transcription factor coordinates Salmonella adaptations to host microenvironments. MBio 5, e1727-14. doi: 10.1128/mBio.01727-14

Brown, S. A., Palmer, K. L., and Whiteley, M. (2008). Revisiting the host as a growth medium. Nat. Rev. Microbiol. 6, 657-666. doi: 10.1038/nrmicro 1955

Brzostek, K., Skorek, K., and Raczkowska, A. (2012). OmpR, a central integrator of several cellular responses in Yersinia enterocolitica. Adv. Exp. Med. Biol. 954, 325-334. doi: 10.1007/978-1-4614-3561-7_40

Buchmeier, N., Bossie, S., Chen, C. Y., Fang, F. C., Guiney, D. G., and Libby, S. J. (1997). SlyA, a transcriptional regulator of Salmonella typhimurium, is required for resistance to oxidative stress and is expressed in the intracellular environment of macrophages. Infect. Immun. 65, 3725-3730.

Bücker, R., Heroven, A. K., Becker, J., Dersch, P., and Wittmann, C. (2014). The pyruvate-tricarboxylic acid cycle node: a focal point of virulence control in the enteric pathogen Yersinia pseudotuberculosis. J. Biol. Chem. 289, 30114-30132. doi: 10.1074/jbc.M114.581348

Bustamante, V. H., Martinez, L. C., Santana, F. J., Knodler, L. A., SteeleMortimer, O., and Puente, J. L. (2008). HilD-mediated transcriptional cross-talk between SPI-1 and SPI-2. Proc. Natl. Acad. Sci. U.S.A. 105, 14591-14596. doi: 10.1073/pnas.0801205105

Campoy, S., Jara, M., Busquets, N., De Rozas, A. M., Badiola, I., and Barbe, J. (2002). Intracellular cyclic AMP concentration is decreased in Salmonella typhimurium fur mutants. Microbiology 148, 1039-1048. doi: 10.1099/00221287-1484-1039

Cathelyn, J. S., Ellison, D. W., Hinchliffe, S. J., Wren, B. W., and Miller, V. L. (2007). The RovA regulons of Yersinia enterocolitica and Yersinia pestis are distinct: evidence that many RovA-regulated genes were acquired more recently than the core genome. Mol. Microbiol. 66, 189-205. doi: 10.1111/j.13652958.2007.05907.x

Chadsey, M. S., Karlinsey, J. E., and Hughes, K. T. (1998). The flagellar anti-sigma factor FlgM actively dissociates Salmonella typhimurium sigma28 RNA polymerase holoenzyme. Genes Dev. 12, 3123-3136. doi: 10.1101/gad.12.19.3123

Chavez, R. G., Alvarez, A. F., Romeo, T., and Georgellis, D. (2010). The physiological stimulus for the BarA sensor kinase. J. Bacteriol. 192, 2009-2012. doi: 10.1128/JB.01685-09

Chen, Y., and Anderson, D. M. (2011). Expression hierarchy in the Yersinia type III secretion system established through YopD recognition of RNA. Mol. Microbiol. 80, 966-980. doi: 10.1111/j.1365-2958.2011.07623.x

Chevance, F. F., and Hughes, K. T. (2008). Coordinating assembly of a bacterial macromolecular machine. Nat. Rev. Microbiol. 6, 455-465. doi: 10.1038/nrmicro1887

Choi, E., Kim, H., Lee, H., Nam, D., Choi, J., and Shin, D. (2014). The iron-sensing Fur regulator controls expression timing and levels of Salmonella pathogenicity island 2 genes in the course of environmental acidification. Infect. Immun. 82, 2203-2210. doi: 10.1128/IAI.01625-13

Chubiz, J. E., Golubeva, Y. A., Lin, D., Miller, L. D., and Slauch, J. M. (2010). FliZ regulates expression of the Salmonella pathogenicity island 1 invasion locus by controlling HilD protein activity in Salmonella enterica serovar typhimurium. J. Bacteriol. 192, 6261-6270. doi: 10.1128/JB.00635-10

Coombes, B. K., Wickham, M. E., Lowden, M. J., Brown, N. F., and Finlay, B. B. (2005). Negative regulation of Salmonella pathogenicity island 2 is required for contextual control of virulence during typhoid. Proc. Natl. Acad. Sci. U.S.A. 102, 17460-17465. doi: 10.1073/pnas.0505401102 
Cornelis, G. R., Boland, A., Boyd, A. P., Geuijen, C., Iriarte, M., Neyt, C., et al. (1998). The virulence plasmid of Yersinia, an antihost genome. Microbiol. Mol. Biol. Rev. 62, 1315-1352.

Cornelis, G., Sluiters, C., De Rouvroit, C. L., and Michiels, T. (1989). Homology between virF, the transcriptional activator of the Yersinia virulence regulon, and AraC, the Escherichia coli arabinose operon regulator. J. Bacteriol. 171, 254-262.

Dandekar, T., Fieselmann, A., Fischer, E., Popp, J., Hensel, M., and Noster, J. (2014). Salmonella-how a metabolic generalist adopts an intracellular lifestyle during infection. Front. Cell. Infect. Microbiol. 4:191. doi: 10.3389/fcimb.2014.00191

Daniels, J. J., Autenrieth, I. B., Ludwig, A., and Goebel, W. (1996). The gene slyA of Salmonella typhimurium is required for destruction of $\mathrm{M}$ cells and intracellular survival but not for invasion or colonization of the murine small intestine. Infect. Immun. 64, 5075-5084.

Davis, K. M., Mohammadi, S., and Isberg, R. R. (2015). Community behavior and spatial regulation within a bacterial microcolony in deep tissue sites serves to protect against host attack. Cell Host Microbe 17, 21-31. doi: 10.1016/j.chom.2014.11.008

Diard, M., Garcia, V., Maier, L., Remus-Emsermann, M. N., Regoes, R. R., Ackermann, M., et al. (2013). Stabilization of cooperative virulence by the expression of an avirulent phenotype. Nature 494, 353-356. doi: 10.1038 /nature 11913

Dillon, S. C., and Dorman, C. J. (2010). Bacterial nucleoid-associated proteins, nucleoid structure and gene expression. Nat. Rev. Microbiol. 8, 185-195. doi: $10.1038 /$ nrmicro2261

Ding, L., Wang, Y., Hu, Y., Atkinson, S., Williams, P., and Chen, S. (2009). Functional characterization of FlgM in the regulation of flagellar synthesis and motility in Yersinia pseudotuberculosis. Microbiology 155, 1890-1900. doi: 10.1099/mic.0.026294-0

Dorman, C. J. (2007). H-NS, the genome sentinel. Nat. Rev. Microbiol. 5, 157-161. doi: $10.1038 / \mathrm{nrmicro} 1598$

Dorman, C. J., Chatfield, S., Higgins, C. F., Hayward, C., and Dougan, G. (1989). Characterization of porin and ompR mutants of a virulent strain of Salmonella typhimurium: ompR mutants are attenuated in vivo. Infect. Immun. 57, 2136-2140.

Dorrell, N., Li, S. R., Everest, P. H., Dougan, G., and Wren, B. W. (1998). Construction and characterisation of a Yersinia enterocolitica O:8 ompR mutant. FEMS Microbiol. Lett. 165, 145-151. doi: 10.1111/j.15746968.1998.tb13139.x

Ellermeier, C. D., Ellermeier, J. R., and Slauch, J. M. (2005). HilD, HilC and RtsA constitute a feed forward loop that controls expression of the SPI1 type three secretion system regulator hilA in Salmonella enterica serovar Typhimurium. Mol. Microbiol. 57, 691-705. doi: 10.1111/j.1365-2958.2005.04737.x

Ellermeier, C. D., and Slauch, J. M. (2003). RtsA and RtsB coordinately regulate expression of the invasion and flagellar genes in Salmonella enterica serovar Typhimurium. J. Bacteriol. 185, 5096-5108. doi: 10.1128/JB.185.17.50965108.2003

Ellermeier, J. R., and Slauch, J. M. (2007). Adaptation to the host environment: regulation of the SPI1 type III secretion system in Salmonella enterica serovar Typhimurium. Curr. Opin. Microbiol. 10, 24-29. doi: 10.1016/j.mib.2006.12.002

Ellermeier, J. R., and Slauch, J. M. (2008). Fur regulates expression of the Salmonella pathogenicity island 1 type III secretion system through HilD. J. Bacteriol. 190, 476-486. doi: 10.1128/JB.00926-07

Ellison, D. W., and Miller, V. L. (2006). H-NS represses inv transcription in Yersinia enterocolitica through competition with RovA and interaction with YmoA. J. Bacteriol. 188, 5101-5112. doi: 10.1128/JB.00862-05

Ellison, D., Young, B., Nelson, K., and Miller, V. L. (2003). YmoA negatively regulates expression of invasin from Yersinia enterocolitica. J. Bacteriol. 185, 7153-7159. doi: 10.1128/JB.185.24.7153-7159.2003

Fabrega, A., and Vila, J. (2013). Salmonella enterica serovar Typhimurium skills to succeed in the host: virulence and regulation. Clin. Microbiol. Rev. 26, 308-341. doi: 10.1128/CMR.00066-12

Fahlen, T. F., Mathur, N., and Jones, B. D. (2000). Identification and characterization of mutants with increased expression of hilA, the invasion gene transcriptional activator of Salmonella typhimurium. FEMS Immunol. Med. Microbiol. 28, 25-35. doi: 10.1111/j.1574-695X.2000.tb01453.x

Fass, E., and Groisman, E. A. (2009). Control of Salmonella pathogenicity island-2 gene expression. Curr. Opin. Microbiol. 12, 199-204. doi: 10.1016/j.mib.2009.01.004
Feng, X., Oropeza, R., and Kenney, L. J. (2003). Dual regulation by phospho-OmpR of ssrA/B gene expression in Salmonella pathogenicity island 2. Mol. Microbiol. 48, 1131-1143. doi: 10.1046/j.1365-2958.2003.03502.x

Flamez, C., Ricard, I., Arafah, S., Simonet, M., and Marceau, M. (2007). Twocomponent system regulon plasticity in bacteria: a concept emerging from phenotypic analysis of Yersinia pseudotuberculosis response regulator mutants. Adv. Exp. Med. Biol. 603, 145-155. doi: 10.1007/978-0-387-72124-8_12

Franchi, L., Amer, A., Body-Malapel, M., Kanneganti, T. D., Ozoren, N., Jagirdar, R., et al. (2006). Cytosolic flagellin requires IpaF for activation of caspase-1 and interleukin lbeta in salmonella-infected macrophages. Nat. Immunol. 7, 576-582. doi: 10.1038/ni1346

Fraser, G. M., Bennett, J. C., and Hughes, C. (1999). Substrate-specific binding of hook-associated proteins by FlgN and FliT, putative chaperones for flagellum assembly. Mol. Microbiol. 32, 569-580. doi: 10.1046/j.1365-2958.1999.01372.x

Fredriksson-Ahomaa, M. (2012). Isolation of enteropathogenic Yersinia from non-human sources. Adv. Exp. Med. Biol. 954, 97-105. doi: 10.1007/978-14614-3561-7_12

Fredriksson-Ahomaa, M., Stolle, A., and Korkeala, H. (2006). Molecular epidemiology of Yersinia enterocolitica infections. FEMS Immunol. Med. Microbiol. 47, 315-329. doi: 10.1111/j.1574-695X.2006.00095.x

Garcia-Calderon, C. B., Casadesus, J., and Ramos-Morales, F. (2007). Rcs and PhoPQ regulatory overlap in the control of Salmonella enterica virulence. J. Bacteriol. 189, 6635-6644. doi: 10.1128/JB.00640-07

Gerlach, R. G., Jackel, D., Geymeier, N., and Hensel, M. (2007). Salmonella pathogenicity island 4-mediated adhesion is coregulated with invasion genes in Salmonella enterica. Infect. Immun. 75, 4697-4709. doi: 10.1128/IAI.00 228-07

Goguen, J. D., Yother, J., and Straley, S. C. (1984). Genetic analysis of the low calcium response in Yersinia pestis mu $\mathrm{d} 1$ (Ap lac) insertion mutants. J. Bacteriol. 160, 842-848.

Golubeva, Y. A., Sadik, A. Y., Ellermeier, J. R., and Slauch, J. M. (2012). Integrating global regulatory input into the Salmonella pathogenicity island 1 type III secretion system. Genetics 190, 79-90. doi: 10.1534/genetics.111.132779

Gorke, B., and Stulke, J. (2008). Carbon catabolite repression in bacteria: many ways to make the most out of nutrients. Nat. Rev. Microbiol. 6, 613-624. doi: 10.1038/nrmicro1932

Grabenstein, J. P., Fukuto, H. S., Palmer, L. E., and Bliska, J. B. (2006). Characterization of phagosome trafficking and identification of PhoP-regulated genes important for survival of Yersinia pestis in macrophages. Infect. Immun. 74, 3727-3741. doi: 10.1128/IAI.00255-06

Grabenstein, J. P., Marceau, M., Pujol, C., Simonet, M., and Bliska, J. B. (2004). The response regulator PhoP of Yersinia pseudotuberculosis is important for replication in macrophages and for virulence. Infect. Immun. 72, 4973-4984. doi: 10.1128/IAI.72.9.4973-4984.200472/9/4973

Grassl, G. A., Bohn, E., Muller, Y., Buhler, O. T., and Autenrieth, I. B. (2003). Interaction of Yersinia enterocolitica with epithelial cells: invasin beyond invasion. Int. J. Med. Microbiol. 293, 41-54. doi: 10.1078/1438-4221-00243

Groisman, E. A. (2001). The pleiotropic two-component regulatory system PhoP-PhoQ. J. Bacteriol. 183, 1835-1842. doi: 10.1128/JB.183.6.1835-184 2.2001

Groisman, E. A., and Mouslim, C. (2006). Sensing by bacterial regulatory systems in host and non-host environments. Nat. Rev. Microbiol. 4, 705-709. doi: 10.1038/nrmicro1478

Grutzkau, A., Hanski, C., Hahn, H., and Riecken, E. O. (1990). Involvement of M cells in the bacterial invasion of Peyer's patches: a common mechanism shared by Yersinia enterocolitica and other enteroinvasive bacteria. Gut 31, 1011-1015. doi: 10.1136/gut.31.9.1011

Gu, W., Wang, X., Qiu, H., Cui, B., Zhao, S., Zheng, H., et al. (2013). Comparison of cytokine immune responses to Brucella abortus and Yersinia enterocolitica serotype O:9 infections in BALB/c mice. Infect. Immun. 81, 4392-4398. doi: 10.1128/IAI.00856-13

Gueguen, E., Durand, E., Zhang, X. Y., D'amalric, Q., Journet, L., and Cascales, E. (2013). Expression of a type VI secretion system is responsive to envelope stresses through the OmpR rranscriptional activator. PLoS ONE 8:e66615. doi: 10.1371/journal.pone.0066615

Hanamura, A., and Aiba, H. (1991). Molecular mechanism of negative autoregulation of Escherichia coli crp gene. Nucleic Acids Res. 19, 4413-4419. doi: $10.1093 /$ nar/19.16.4413 
Handley, S. A., Newberry, R. D., and Miller, V. L. (2005). Yersinia enterocolitica invasin-dependent and invasin-independent mechanisms of systemic dissemination. Infect. Immun. 73, 8453-8455. doi: 10.1128/IAI.73.12.8453-8455.2005

Hayashi, F., Smith, K. D., Ozinsky, A., Hawn, T. R., Yi, E. C., Goodlett, D. R., et al. (2001). The innate immune response to bacterial flagellin is mediated by Toll-like receptor 5. Nature 410, 1099-1103. doi: 10.1038/35074106

Heeb, S., and Haas, D. (2001). Regulatory roles of the GacS/GacA two-component system in plant-associated and other gram-negative bacteria. Mol. Plant Microbe Interact. 14, 1351-1363. doi: 10.1094/MPMI.2001.14.12.1351

Heise, T., and Dersch, P. (2006). Identification of a domain in Yersinia virulence factor YadA that is crucial for extracellular matrix-specific cell adhesion and uptake. Proc. Natl. Acad. Sci. U.S.A. 103, 3375-3380. doi: 10.1073/pnas.0507749103

Herbst, K., Bujara, M., Heroven, A. K., Opitz, W., Weichert, M., Zimmermann, A., et al. (2009). Intrinsic thermal sensing controls proteolysis of Yersinia virulence regulator RovA. PLoS Pathog. 5:e1000435. doi: 10.1371/journal.ppat.1000435

Heroven, A. K., Bohme, K., and Dersch, P. (2012a). The Csr/Rsm system of Yersinia and related pathogens: a post-transcriptional strategy for managing virulence. RNA Biol. 9, 379-391. doi: 10.4161/rna.19333

Heroven, A. K., Sest, M., Pisano, F., Scheb-Wetzel, M., Steinmann, R., Bohme, K., et al. (2012b). Crp induces switching of the CsrB and CsrC RNAs in Yersinia pseudotuberculosis and links nutritional status to virulence. Front. Cell. Infect. Microbiol. 2:158. doi: 10.3389/fcimb.2012.00158

Heroven, A., Bohme, K., Rohde, M., and Dersch, P. (2008). A Csr-type regulatory system, including small non-coding RNAs, regulates the global virulence regulator RovA of Yersinia pseudotuberculosis through RovM. Mol. Microbiol. 68, 1179-1195. doi: 10.1111/j.1365-2958.2008.06218.x

Heroven, A., Bohme, K., Tran-Winkler, H., and Dersch, P. (2007). Regulatory elements implicated in the environmental control of invasin expression in enteropathogenic Yersinia. Adv. Exp. Med. Biol. 603, 156-166. doi: 10.1007/9780-387-72124-8_13

Heroven, A., Nagel, G., Tran, H. J., Parr, S., and Dersch, P. (2004). RovA is autoregulated and antagonizes H-NS-mediated silencing of invasin and rovA expression in Yersinia pseudotuberculosis. Mol. Microbiol. 53, 871-888. doi: 10.1111/j.1365-2958.2004.04162.x

Heroven, A. K., and Dersch, P. (2006). RovM, a novel LysR-type regulator of the virulence activator gene rovA, controls cell invasion, virulence and motility of Yersinia pseudotuberculosis. Mol. Microbiol. 62, 1469-1483. doi: 10.1111/j.13652958.2006.05458.x

Heroven, A. K., and Dersch, P. (2014). Coregulation of host-adapted metabolism and virulence by pathogenic yersiniae. Front. Cell. Infect. Microbiol. 4:146. doi: 10.3389/fcimb. 2014.00146

Hoe, N. P., and Goguen, J. D. (1993). Temperature sensing in Yersinia pestis: translation of the LcrF activator protein is thermally regulated. J. Bacteriol. 175 , 7901-7909.

Hoelzer, K., Moreno Switt, A. I., and Wiedmann, M. (2011). Animal contact as a source of human non-typhoidal salmonellosis. Vet. Res. 42, 34. doi: 10.1186/1297-9716-42-34

Horne, S. M., and Pruss, B. M. (2006). Global gene regulation in Yersinia enterocolitica: effect of FliA on the expression levels of flagellar and plasmidencoded virulence genes. Arch. Microbiol. 185, 115-126. doi: 10.1007/s00203005-0077-1

Hu, Y., Wang, Y., Ding, L., Lu, P., Atkinson, S., and Chen, S. (2009). Positive regulation of flhDC expression by OmpR in Yersinia pseudotuberculosis. Microbiology 155, 3622-3631. doi: 10.1099/mic.0.030908-0

Hughes, K. T., Gillen, K. L., Semon, M. J., and Karlinsey, J. E. (1993). Sensing structural intermediates in bacterial flagellar assembly by export of a negative regulator. Science 262, 1277-1280. doi: $10.1126 /$ science.823 5660

Iriarte, M., Stainier, I., Mikulskis, A. V., and Cornelis, G. R. (1995). The fliA gene encoding sigma 28 in Yersinia enterocolitica. J. Bacteriol. 177, 2299-2304.

Isberg, R. R., Swain, A., and Falkow, S. (1988). Analysis of expression and thermoregulation of the Yersinia pseudotuberculosis inv gene with hybrid proteins. Infect. Immun. 56, 2133-2138.

Ishizuka, H., Hanamura, A., Inada, T., and Aiba, H. (1994). Mechanism of the down-regulation of cAMP receptor protein by glucose in Escherichia coli: role of autoregulation of the crp gene. EMBO J. 13, 3077-3082.
Iyoda, S., Kamidoi, T., Hirose, K., Kutsukake, K., and Watanabe, H. (2001). A flagellar gene fliZ regulates the expression of invasion genes and virulence phenotype in Salmonella enterica serovar Typhimurium. Microb. Pathog. 30, 81-90. doi: 10.1006/mpat.2000.0409

Jackson, M., Silva-Herzog, E., and Plano, G. V. (2004). The ATP-dependent ClpXP and Lon proteases regulate expression of the Yersinia pestis type III secretion system via regulated proteolysis of YmoA, a small histone-like protein. Mol. Microbiol. 54, 1364-1378. doi: 10.1111/j.1365-2958.2004.04353.x

Jonas, K., Edwards, A. N., Ahmad, I., Romeo, T., Romling, U., and Melefors, O. (2010). Complex regulatory network encompassing the Csr, c-di-GMP and motility systems of Salmonella Typhimurium. Environ. Microbiol. 12, 524-540. doi: 10.1111/j.1462-2920.2009.02097.x

Jones, B. D., Ghori, N., and Falkow, S. (1994). Salmonella typhimurium initiates murine infection by penetrating and destroying the specialized epithelial M cells of the Peyer's patches. J. Exp. Med. 180, 15-23. doi: 10.1084/jem.180.1.15

Kage, H., Takaya, A., Ohya, M., and Yamamoto, T. (2008). Coordinated regulation of expression of Salmonella pathogenicity island 1 and flagellar type III secretion systems by ATP-dependent ClpXP protease. J. Bacteriol. 190, 2470-2478. doi: 10.1128/JB.01385-07

Kapatral, V., Campbell, J. W., Minnich, S. A., Thomson, N. R., Matsumura, P., and Pruss, B. M. (2004). Gene array analysis of Yersinia enterocolitica FlhD and FlhC: regulation of enzymes affecting synthesis and degradation of carbamoylphosphate. Microbiology 150, 2289-2300. doi: 10.1099/mic.0.26814$0150 / 7 / 2289$

Kapatral, V., Olson, J. W., Pepe, J. C., Miller, V. L., and Minnich, S. A. (1996). Temperature-dependent regulation of Yersinia enterocolitica Class III flagellar genes. Mol. Microbiol. 19, 1061-1071. doi: 10.1046/j.1365-2958.1996.45 2978.x

Karlinsey, J. E., Tanaka, S., Bettenworth, V., Yamaguchi, S., Boos, W., Aizawa, S. I., et al. (2000). Completion of the hook-basal body complex of the Salmonella typhimurium flagellum is coupled to FlgM secretion and fliC transcription. Mol. Microbiol. 37, 1220-1231. doi: 10.1046/j.1365-2958.20 00.02081.x

Kelly, A., Goldberg, M. D., Carroll, R. K., Danino, V., Hinton, J. C., and Dorman, C. J. (2004). A global role for Fis in the transcriptional control of metabolism and type III secretion in Salmonella enterica serovar Typhimurium. Microbiology 150, 2037-2053. doi: 10.1099/mic.0.27209-0

Komeda, Y., Suzuki, H., Ishidsu, J. I., and Iino, T. (1976). The role of cAMP in flagellation of Salmonella typhimurium. Mol. Gen. Genet. 142, 289-298.

Koornhof, H. J., Smego, R. A. Jr., and Nicol, M. (1999). Yersiniosis. II: the pathogenesis of Yersinia infections. Eur. J. Clin. Microbiol. Infect. Dis. 18, 87-112.

Kopaskie, K. S., Ligtenberg, K. G., and Schneewind, O. (2013). Translational regulation of Yersinia enterocolitica mRNA encoding a type III secretion substrate. J. Biol. Chem. 288, 35478-35488. doi: 10.1074/jbc.M113.504811

Kröger, C., Colgan, A., Srikumar, S., Handler, K., Sivasankaran, S. K., Hammarlof, D. L., et al. (2013). An infection-relevant transcriptomic compendium for Salmonella enterica Serovar Typhimurium. Cell Host Microbe 14, 683-695. doi: 10.1016/j.chom.2013.11.010

Kröger, C., Dillon, S. C., Cameron, A. D., Papenfort, K., Sivasankaran, S. K., Hokamp, K., et al. (2012). The transcriptional landscape and small RNAs of Salmonella enterica serovar Typhimurium. Proc. Natl. Acad. Sci. U.S.A. 109, E1277-E1286. doi: 10.1073/pnas.1201061109

Kutsukake, K. (1994). Excretion of the anti-sigma factor through a flagellar substructure couples flagellar gene expression with flagellar assembly in Salmonella typhimurium. Mol. Gen. Genet. 243, 605-612.

Kutsukake, K., Ikebe, T., and Yamamoto, S. (1999). Two novel regulatory genes, fliT and fliZ, in the flagellar regulon of Salmonella. Genes Genet. Syst. 74, 287-292. doi: $10.1266 /$ ggs.74.287

Lapouge, K., Schubert, M., Allain, F. H., and Haas, D. (2007). Gac/Rsm signal transduction pathway of gamma-proteobacteria: from RNA recognition to regulation of social behaviour. Mol. Microbiol. 67, 241-253. doi: 10.1111/j.13652958.2007.06042.x

Lawhon, S. D., Frye, J. G., Suyemoto, M., Porwollik, S., Mcclelland, M., and Altier, C. (2003). Global regulation by CsrA in Salmonella typhimurium. Mol. Microbiol. 48, 1633-1645. doi: 10.1046/j.1365-2958.2003.03535.x

Lawhon, S. D., Maurer, R., Suyemoto, M., and Altier, C. (2002). Intestinal short-chain fatty acids alter Salmonella typhimurium invasion gene expression 
and virulence through BarA/SirA. Mol. Microbiol. 46, 1451-1464. doi: 10.1046/j.1365-2958.2002.03268.x

Lee, A. K., Detweiler, C. S., and Falkow, S. (2000). OmpR regulates the twocomponent system SsrA-ssrB in Salmonella pathogenicity island 2. J. Bacteriol. 182, 771-781. doi: 10.1128/JB.182.3.771-781.2000

Lee, C. A., Jones, B. D., and Falkow, S. (1992). Identification of a Salmonella typhimurium invasion locus by selection for hyperinvasive mutants. Proc. Natl. Acad. Sci. U.S.A. 89, 1847-1851. doi: 10.1073/pnas.89.5.1847

LeGrand, K., Petersen, S., Zheng, Y., Liu, K. K., Ozturk, G., Chen, J. Y., et al. (2015). CsrA impacts survival of Yersinia enterocolitica by affecting a myriad of physiological activities. BMC Microbiol. 15:31. doi: 10.1186/s12866-015-0343-6

Li, Y., Hu, Y., Francis, M. S., and Chen, S. (2015). RcsB positively regulates the Yersinia Ysc-Yop type III secretion system by activating expression of the master transcriptional regulator LcrF. Environ. Microbiol. 17, 1219-1233. doi: $10.1111 / 1462-2920.12556$

Libby, S. J., Goebel, W., Ludwig, A., Buchmeier, N., Bowe, F., Fang, F. C., et al. (1994). A cytolysin encoded by Salmonella is required for survival within macrophages. Proc. Natl. Acad. Sci. U.S.A. 91, 489-493. doi: 10.1073/pnas.91.2.489

Lim, S., Kim, B., Choi, H. S., Lee, Y., and Ryu, S. (2006). Fis is required for proper regulation of ssaG expression in Salmonella enterica serovar Typhimurium. Microb. Pathog. 41, 33-42. doi: 10.1016/j.micpath.2006.03.005

Liu, J., Thanikkal, E. J., Obi, I. R., and Francis, M. S. (2012). Elevated CpxR $\sim$ P levels repress the Ysc-Yop type III secretion system of Yersinia pseudotuberculosis. Res. Microbiol. 163, 518-530. doi: 10.1016/j.resmic.2012.07.010

Liu, X., and Matsumura, P. (1994). The FlhD/FlhC complex, a transcriptional activator of the Escherichia coli flagellar class II operons. J. Bacteriol. 176, 7345-7351.

Liu, X., and Matsumura, P. (1995). An alternative sigma factor controls transcription of flagellar class-III operons in Escherichia coli: gene sequence, overproduction, purification and characterization. Gene 164, 81-84. doi: 10.1016/0378-1119(95)00480-T

Lopez-Garrido, J., Puerta-Fernandez, E., and Casadesus, J. (2014). A eukaryoticlike 3' untranslated region in Salmonella enterica hilD mRNA. Nucleic Acids Res. 42, 5894-5906. doi: 10.1093/nar/gku222

Lucas, R. L., Lostroh, C. P., Dirusso, C. C., Spector, M. P., Wanner, B. L., and Lee, C. A. (2000). Multiple factors independently regulate hilA and invasion gene expression in Salmonella enterica serovar typhimurium. J. Bacteriol. 182, 1872-1882. doi: 10.1128/JB.182.7.1872-1882.2000

Madrid, C., Balsalobre, C., Garcia, J., and Juarez, A. (2006). The novel Hha/YmoA family of nucleoid-associated proteins: use of structural mimicry to modulate the activity of the H-NS family of proteins. Mol. Microbiol. 63, 7-14. doi: 10.1111/j.1365-2958.2006.05497.x

Mangan, M. W., Lucchini, S., Danino, V., Croinin, T. O., Hinton, J. C., and Dorman, C. J. (2006). The integration host factor (IHF) integrates stationary-phase and virulence gene expression in Salmonella enterica serovar Typhimurium. Mol. Microbiol. 59, 1831-1847. doi: 10.1111/j.13652958.2006.05062.x

Marra, A., and Isberg, R. R. (1997). Invasin-dependent and invasin-independent pathways for translocation of Yersinia pseudotuberculosis across the Peyer's patch intestinal epithelium. Infect. Immun. 65, 3412-3421.

Martinez, L. C., Yakhnin, H., Camacho, M. I., Georgellis, D., Babitzke, P., Puente, J. L., et al. (2011). Integration of a complex regulatory cascade involving the SirA/BarA and Csr global regulatory systems that controls expression of the Salmonella SPI-1 and SPI-2 virulence regulons through HilD. Mol. Microbiol. 80, 1637-1656. doi: 10.1111/j.1365-2958.2011.07674.x

Mercante, J., Edwards, A. N., Dubey, A. K., Babitzke, P., and Romeo, T. (2009). Molecular geometry of CsrA (RsmA) binding to RNA and its implications for regulated expression. J. Mol. Biol. 392, 511-528. doi: 10.1016/j.jmb.2009.07.034

Miao, E. A., Alpuche-Aranda, C. M., Dors, M., Clark, A. E., Bader, M. W., Miller, S. I., et al. (2006). Cytoplasmic flagellin activates caspase-1 and secretion of interleukin 1beta via IpaF. Nat. Immunol. 7, 569-575. doi: 10.103 8/ni1344

Miao, E. A., Freeman, J. A., and Miller, S. I. (2002). Transcription of the $\mathrm{Ssr} \mathrm{AB}$ regulon is repressed by alkaline $\mathrm{pH}$ and is independent of PhoPQ and magnesium concentration. J. Bacteriol. 184, 1493-1497. doi: 10.1128/JB.184.5.1493-1497.2002
Michiels, T., Vanooteghem, J. C., Lambert De Rouvroit, C., China, B., Gustin, A., Boudry, P., et al. (1991). Analysis of virC, an operon involved in the secretion of Yop proteins by Yersinia enterocolitica. J. Bacteriol. 173, 4994-5009.

Miller, H. K., Kwuan, L., Schwiesow, L., Bernick, D. L., Mettert, E., Ramirez, H. A., et al. (2014). IscR is essential for Yersinia pseudotuberculosis type III secretion and virulence. PLoS Pathog. 10:e1004194. doi: 10.1371/journal.ppat.1004194

Miller, S. I., Kukral, A. M., and Mekalanos, J. J. (1989). A two-component regulatory system (phoP phoQ) controls Salmonella typhimurium virulence. Proc. Natl. Acad. Sci. U.S.A. 86, 5054-5058. doi: 10.1073/pnas.86.13.5054

Mouslim, C., and Hughes, K. T. (2014). The effect of cell growth phase on the regulatory cross-talk between flagellar and Spi1 virulence gene expression. PLoS Pathog. 10:e1003987. doi: 10.1371/journal.ppat.1003987

Mulder, D. T., Mcphee, J. B., Reid-Yu, S. A., Stogios, P. J., Savchenko, A., and Coombes, B. K. (2015). Multiple histidines in the periplasmic domain of the Salmonella enterica sensor kinase SsrA enhance signaling in response to extracellular acidification. Mol. Microbiol. 95, 678-691. doi: 10.1111/mmi.12895

Nagel, G., Lahrz, A., and Dersch, P. (2001). Environmental control of invasin expression in Yersinia pseudotuberculosis is mediated by regulation of RovA, a transcriptional activator of the SlyA/Hor family. Mol. Microbiol. 41, 1249-1269. doi: 10.1046/j.1365-2958.2001.02522.x

Navarre, W. W., Porwollik, S., Wang, Y., Mcclelland, M., Rosen, H., Libby, S. J., et al. (2006). Selective silencing of foreign DNA with low GC content by the H-NS protein in Salmonella. Science 313, 236-238. doi: 10.1126/science. 1128794

Nizet, V., and Johnson, R. S. (2009). Interdependence of hypoxic and innate immune responses. Nat. Rev. Immunol. 9, 609-617. doi: 10.1038/nri2607

Nuss, A. M., Heroven, A. K., Waldmann, B., Reinkensmeier, J., Jarek, M., Beckstette, M., et al. (2015). Transcriptomic profiling of Yersinia pseudotuberculosis reveals reprogramming of the Crp regulon by temperature and uncovers Crp as a master regulator of small RNAs. PLoS Genet. 11:e1005087. doi: 10.1371/journal.pgen.1005087

Nuss, A. M., Schuster, F., Kathrin Heroven, A., Heine, W., Pisano, F., and Dersch, P. (2014). A direct link between the global regulator PhoP and the Csr regulon in Y. pseudotuberculosis through the small regulatory RNA CsrC. RNA Biol. 11, 580-593. doi: 10.4161/rna.28676

O Croinin, T., Carroll, R. K., Kelly, A., and Dorman, C. J. (2006). Roles for DNA supercoiling and the Fis protein in modulating expression of virulence genes during intracellular growth of Salmonella enterica serovar Typhimurium. Mol. Microbiol. 62, 869-882. doi: 10.1111/j.1365-2958.2006.05416.x

Ohl, M. E., and Miller, S. I. (2001). Salmonella: a model for bacterial pathogenesis. Annu. Rev. Med. 52, 259-274. doi: 10.1146/annurev.med.52.1.259

Ohnishi, K., Kutsukake, K., Suzuki, H., and Lino, T. (1992). A novel transcriptional regulation mechanism in the flagellar regulon of Salmonella typhimurium: an antisigma factor inhibits the activity of the flagellum-specific sigma factor, sigma F. Mol. Microbiol. 6, 3149-3157. doi: 10.1111/j.1365-2958.1992.tb01771.x

Okada, N., Oi, Y., Takeda-Shitaka, M., Kanou, K., Umeyama, H., Haneda, T., et al. (2007). Identification of amino acid residues of Salmonella SlyA that are critical for transcriptional regulation. Microbiology 153, 548-560. doi: 10.1099/mic.0.29259-0

Olekhnovich, I. N., and Kadner, R. J. (2002). DNA-binding activities of the HilC and HilD virulence regulatory proteins of Salmonella enterica serovar Typhimurium. J. Bacteriol. 184, 4148-4160. doi: 10.1128/JB.184.15.41484160.2002

Olekhnovich, I. N., and Kadner, R. J. (2006). Crucial roles of both flanking sequences in silencing of the hilA promoter in Salmonella enterica. J. Mol. Biol. 357, 373-386. doi: 10.1016/j.jmb.2006.01.007

Olekhnovich, I. N., and Kadner, R. J. (2007). Role of nucleoid-associated proteins Hha and H-NS in expression of Salmonella enterica activators HilD, HilC, and RtsA required for cell invasion. J. Bacteriol. 189, 6882-6890. doi: 10.1128/JB.00905-07

Pegues, D. A., Hantman, M. J., Behlau, I., and Miller, S. I. (1995). PhoP/PhoQ transcriptional repression of Salmonella typhimurium invasion genes: evidence for a role in protein secretion. Mol. Microbiol. 17, 169-181. doi: 10.1111/j.13652958.1995.mmi_17010169.x

Pepe, J. C., Badger, J. L., and Miller, V. L. (1994). Growth phase and low pH affect the thermal regulation of the Yersinia enterocolitica inv gene. Mol. Microbiol. 11, 123-135. doi: 10.1111/j.1365-2958.1994.tb00295.x 
Perez, J. C., and Groisman, E. A. (2009). Transcription factor function and promoter architecture govern the evolution of bacterial regulons. Proc. Natl. Acad. Sci. U.S.A. 106, 4319-4324. doi: 10.1073/pnas.0810343106

Petersen, S., and Young, G. M. (2002). Essential role for cyclic AMP and its receptor protein in Yersinia enterocolitica virulence. Infect. Immun. 70, 3665-3672. doi: 10.1128/IAI.70.7.3665-3672.2002

Pettersson, J., Nordfelth, R., Dubinina, E., Bergman, T., Gustafsson, M., Magnusson, K. E., et al. (1996). Modulation of virulence factor expression by pathogen target cell contact. Science 273, 1231-1233. doi: $10.1126 /$ science. 273.5279 .1231

Pisano, F., Heine, W., Rosenheinrich, M., Schweer, J., Nuss, A. M., and Dersch, P. (2014). Influence of PhoP and intra-species variations on virulence of Yersinia pseudotuberculosis during the natural oral infection route. PLoS ONE 9:e103541. doi: 10.1371 /journal.pone. 0103541

Poncet, S., Milohanic, E., Maze, A., Abdallah, J. N., Ake, F., Larribe, M., et al. (2009). Correlations between carbon metabolism and virulence in bacteria. Contrib. Microbiol. 16, 88-102. doi: 10.1159/000219374

Quade, N., Mendonca, C., Herbst, K., Heroven, A. K., Ritter, C., Heinz, D. W., et al. (2012). Structural basis for intrinsic thermosensing by the master virulence regulator RovA of Yersinia. J. Biol. Chem. 287, 35796-35803. doi: 10.1074/jbc.M112.379156

Raczkowska, A., Brzostkowska, M., Kwiatek, A., Bielecki, J., and Brzostek, K. (2011a). Modulation of inv gene expression by the OmpR two-component response regulator protein of Yersinia enterocolitica. Folia Microbiol. (Praha) 56, 313-319. doi: 10.1007/s12223-011-0054-9

Raczkowska, A., Skorek, K., Bielecki, J., and Brzostek, K. (2011b). OmpR controls Yersinia enterocolitica motility by positive regulation of flhDC expression. Antonie Van Leeuwenhoek 99, 381-394. doi: 10.1007/s10482-010-9503-8

Raczkowska, A., Trzos, J., Lewandowska, O., Nieckarz, M., and Brzostek, K. (2015). Expression of the AcrAB components of the AcrAB-TolC multidrug efflux pump of Yersinia enterocolitica is subject to dual regulation by OmpR. PLoS ONE 10:e0124248. doi: 10.1371/journal.pone.0124248

Reines, M., Llobet, E., Llompart, C. M., Moranta, D., Perez-Gutierrez, C., and Bengoechea, J. A. (2012). Molecular basis of Yersinia enterocolitica temperaturedependent resistance to antimicrobial peptides. J. Bacteriol. 194, 3173-3188. doi: 10.1128/JB.00308-12

Revell, P. A., and Miller, V. L. (2000). A chromosomally encoded regulator is required for expression of the Yersinia enterocolitica inv gene and for virulence. Mol. Microbiol. 35, 677-685. doi: 10.1046/j.1365-2958.2000. 01740.x

Rohde, J. R., Fox, J. M., and Minnich, S. A. (1994). Thermoregulation in Yersinia enterocolitica is coincident with changes in DNA supercoiling. Mol. Microbiol. 12, 187-199. doi: 10.1111/j.1365-2958.1994.tb01008.x

Rohde, J. R., Luan, X. S., Rohde, H., Fox, J. M., and Minnich, S. A. (1999). The Yersinia enterocolitica pYV virulence plasmid contains multiple intrinsic DNA bends which melt at 37 degrees C. J. Bacteriol. 181, 4198-4204.

Rohmer, L., Hocquet, D., and Miller, S. I. (2011). Are pathogenic bacteria just looking for food? Metabolism and microbial pathogenesis. Trends Microbiol. 19, 341-348. doi: 10.1016/j.tim.2011.04.003

Romeo, T., Vakulskas, C. A., and Babitzke, P. (2012). Post-transcriptional regulation on a global scale: form and function of Csr/Rsm systems. Environ. Microbiol. 15, 313-324. doi: 10.1111/j.1462-2920.2012.02794.x

Romeo, T., Vakulskas, C. A., and Babitzke, P. (2013). Post-transcriptional regulation on a global scale: form and function of Csr/Rsm systems. Environ. Microbiol. 15, 313-324. doi: 10.1111/j.1462-2920.2012.02794.x

Saini, S., Slauch, J. M., Aldridge, P. D., and Rao, C. V. (2010). Role of cross talk in regulating the dynamic expression of the flagellar Salmonella pathogenicity island 1 and type 1 fimbrial genes. J. Bacteriol. 192, 5767-5777. doi: 10.1128/JB.00624-10

Sato, Y., Takaya, A., Mouslim, C., Hughes, K. T., and Yamamoto, T. (2014). FliT selectively enhances proteolysis of FlhC subunit in FlhD4C2 complex by an ATP-dependent protease, ClpXP. J. Biol. Chem. 289, 33001-33011. doi: 10.1074/jbc.M114.593749

Schaake, J., Drees, A., Gruning, P., Uliczka, F., Pisano, F., Thiermann, T., et al. (2014). Essential role of invasin for colonization and persistence of Yersinia enterocolitica in its natural reservoir host, the pig. Infect. Immun. 82, 960-969. doi: 10.1128/IAI.01001-13
Schaake, J., Kronshage, M., Uliczka, F., Rohde, M., Knuuti, T., Strauch, E., et al. (2013). Human and animal isolates of Yersinia enterocolitica show significant serotype-specific colonization and host-specific immune defense properties. Infect. Immun. 81, 4013-4025. doi: 10.1128/IAI.00572-13

Schechter, L. M., and Lee, C. A. (2001). AraC/XylS family members, HilC and HilD, directly bind and derepress the Salmonella typhimurium hilA promoter. Mol. Microbiol. 40, 1289-1299.

Silphaduang, U., Mascarenhas, M., Karmali, M., and Coombes, B. K. (2007). Repression of intracellular virulence factors in Salmonella by the Hha and YdgT nucleoid-associated proteins. J. Bacteriol. 189, 3669-3673. doi: 10.1128/JB.00002-07

Singer, H. M., Erhardt, M., and Hughes, K. T. (2013). RflM functions as a transcriptional repressor in the autogenous control of the Salmonella flagellar master operon flhDC. J. Bacteriol. 195, 4274-4282. doi: 10.1128/JB.00728-13

Singer, H. M., Kuhne, C., Deditius, J. A., Hughes, K. T., and Erhardt, M. (2014). The Salmonella Spil virulence regulatory protein HilD directly activates transcription of the flagellar master operon flhDC. J. Bacteriol. 196, 1448-1457. doi: 10.1128/JB.01438-13

Skorek, K., Raczkowska, A., Dudek, B., Mietka, K., Guz-Regner, K., Pawlak, A., et al. (2013). Regulatory protein OmpR influences the serum resistance of Yersinia enterocolitica $\mathrm{O}: 9$ by modifying the structure of the outer membrane. PLOS ONE 8:e79525. doi: 10.1371/journal.pone.0079525

Stainier, I., Iriarte, M., and Cornelis, G. R. (1997). YscM1 and YscM2, two Yersinia enterocolitica proteins causing downregulation of yop transcription. Mol. Microbiol. 26, 833-843. doi: 10.1046/j.1365-2958.1997.62 81995.x

Stecher, B., Barthel, M., Schlumberger, M. C., Haberli, L., Rabsch, W., Kremer, M., et al. (2008). Motility allows S. Typhimurium to benefit from the mucosal defence. Cell. Microbiol. 10, 1166-1180. doi: 10.1111/j.1462-5822.2008.01118.x

Stecher, B., Hapfelmeier, S., Muller, C., Kremer, M., Stallmach, T., and Hardt, W. D. (2004). Flagella and chemotaxis are required for efficient induction of Salmonella enterica serovar Typhimurium colitis in streptomycinpretreated mice. Infect. Immun. 72, 4138-4150. doi: 10.1128/IAI.72.7.4138-415 0.2004

Steinmann, R., and Dersch, P. (2013). Thermosensing to adjust bacterial virulence in a fluctuating environment. Future Microbiol. 8, 85-105. doi: $10.2217 / \mathrm{fmb} .12 .129$

Stoebel, D. M., Free, A., and Dorman, C. J. (2008). Anti-silencing: overcoming H-NS-mediated repression of transcription in Gram-negative enteric bacteria. Microbiology 154, 2533-2545. doi: 10.1099/mic.0.2008/020693-0

Straley, S. C., Plano, G. V., Skrzypek, E., Haddix, P. L., and Fields, K. A. (1993). Regulation by $\mathrm{Ca} 2+$ in the Yersinia low-Ca2+ response. Mol. Microbiol. 8, 1005-1010. doi: 10.1111/j.1365-2958.1993.tb01644.x

Takaya, A., Erhardt, M., Karata, K., Winterberg, K., Yamamoto, T., and Hughes, K. T. (2012). YdiV: a dual function protein that targets FlhDC for ClpXP-dependent degradation by promoting release of DNA-bound FlhDC complex. Mol. Microbiol. 83, 1268-1284. doi: 10.1111/j.1365-2958.2012.0 8007.x

Takeuchi, K., Kiefer, P., Reimmann, C., Keel, C., Dubuis, C., Rolli, J., et al. (2009). Small RNA-dependent expression of secondary metabolism is controlled by Krebs cycle function in Pseudomonas fluorescens. J. Biol. Chem. 284, 34976-34985. doi: 10.1074/jbc.M109.052571

Teixido, L., Carrasco, B., Alonso, J. C., Barbe, J., and Campoy, S. (2011). Fur activates the expression of Salmonella enterica pathogenicity island 1 by directly interacting with the hilD operator in vivo and in vitro. PLOS ONE 6:e19711. doi: 10.1371/journal.pone.0019711

Teplitski, M., Goodier, R. I., and Ahmer, B. M. (2003). Pathways leading from BarA/SirA to motility and virulence gene expression in Salmonella. J. Bacteriol. 185, 7257-7265. doi: 10.1128/JB.185.24.7257-7265.2003

Teplitski, M., Goodier, R. I., and Ahmer, B. M. (2006). Catabolite repression of the SirA regulatory cascade in Salmonella enterica. Int. J. Med. Microbiol. 296, 449-466. doi: 10.1016/j.ijmm.2006.06.001

Tran, H. J., Heroven, A. K., Winkler, L., Spreter, T., Beatrix, B., and Dersch, P. (2005). Analysis of RovA, a transcriptional regulator of Yersinia pseudotuberculosis virulence that acts through antirepression and direct transcriptional activation. J. Biol. Chem. 280, 42423-42432. doi: 10.1074/jbc.M504464200 
Troxell, B., Sikes, M. L., Fink, R. C., Vazquez-Torres, A., Jones-Carson, J., and Hassan, H. M. (2011). Fur negatively regulates hns and is required for the expression of HilA and virulence in Salmonella enterica serovar Typhimurium. J. Bacteriol. 193, 497-505. doi: 10.1128/JB.00942-10

Tsai, C. S., and Winans, S. C. (2011). The quorum-hindered transcription factor YenR of Yersinia enterocolitica inhibits pheromone production and promotes motility via a small non-coding RNA. Mol. Microbiol. 80, 556-571. doi: 10.1111/j.1365-2958.2011.07595.x

Tsolis, R. M., Young, G. M., Solnick, J. V., and Baumler, A. J. (2008). From bench to bedside: stealth of enteroinvasive pathogens. Nat. Rev. Microbiol. 6, 883-892. doi: $10.1038 /$ nrmicro2012

Uliczka, F., and Dersch, P. (2012). Unique virulence properties of Yersinia enterocolitica O:3. Adv. Exp. Med. Biol. 954, 281-287. doi: 10.1007/978-1-46143561-7_35

Vakulskas, C. A., Potts, A. H., Babitzke, P., Ahmer, B. M., and Romeo, T. (2015). Regulation of bacterial virulence by Csr (Rsm) systems. Microbiol. Mol. Biol. Rev. 79, 193-224. doi: 10.1128/MMBR.00052-14

Valentin-Weigand, P., Heesemann, J., and Dersch, P. (2014). Unique virulence properties of Yersinia enterocolitica O:3-an emerging zoonotic pathogen using pigs as preferred reservoir host. Int. J. Med. Microbiol. 304, 824-834. doi: 10.1016/j.ijmm.2014.07.008

Wada, T., Hatamoto, Y., and Kutsukake, K. (2012). Functional and expressional analyses of the anti-FlhD4C2 factor gene ydiV in Escherichia coli. Microbiology 158, 1533-1542. doi: 10.1099/mic.0.056036-0

Wada, T., Morizane, T., Abo, T., Tominaga, A., Inoue-Tanaka, K., and Kutsukake, K. (2011a). EAL domain protein YdiV acts as an antiFlhD4C2 factor responsible for nutritional control of the flagellar regulon in Salmonella enterica Serovar Typhimurium. J. Bacteriol. 193, 1600-1611. doi: 10.1128/JB.01494-10

Wada, T., Tanabe, Y., and Kutsukake, K. (2011b). FliZ acts as a repressor of the ydiV gene, which encodes an anti-FlhD4C2 factor of the flagellar regulon in Salmonella enterica serovar typhimurium. J. Bacteriol. 193, 5191-5198. doi: 10.1128/JB.05441-11

Walthers, D., Carroll, R. K., Navarre, W. W., Libby, S. J., Fang, F. C., and Kenney, L. J. (2007). The response regulator SsrB activates expression of diverse Salmonella pathogenicity island 2 promoters and counters silencing by the nucleoid-associated protein H-NS. Mol. Microbiol. 65, 477-493. doi: 10.1111/j.1365-2958.2007.05800.x

Wang, H., Liu, B., Wang, Q., and Wang, L. (2013). Genome-wide analysis of the Salmonella Fis regulon and its regulatory mechanism on pathogenicity islands. PLOS ONE 8:e64688. doi: 10.1371/journal.pone.0064688

Wang, Q., Zhao, Y., Mcclelland, M., and Harshey, R. M. (2007). The RcsCDB signaling system and swarming motility in Salmonella enterica serovar typhimurium: dual regulation of flagellar and SPI-2 virulence genes. J. Bacteriol. 189, 8447-8457. doi: 10.1128/JB.01198-07

Wang, S., Fleming, R. T., Westbrook, E. M., Matsumura, P., and Mckay, D. B. (2006). Structure of the Escherichia coli FlhDC complex, a prokaryotic heteromeric regulator of transcription. J. Mol. Biol. 355, 798-808. doi: 10.1016/j.jmb.2005.11.020
Watson, P. R., Paulin, S. M., Bland, A. P., Libby, S. J., Jones, P. W., and Wallis, T. S. (1999). Differential regulation of enteric and systemic salmonellosis by slyA. Infect. Immun. 67, 4950-4954.

Wiedemann, A., Virlogeux-Payant, I., Chausse, A. M., Schikora, A., and Velge, P. (2014). Interactions of Salmonella with animals and plants. Front. Microbiol. 5:791. doi: 10.3389/fmicb.2014.00791

Wilson, R. L., Libby, S. J., Freet, A. M., Boddicker, J. D., Fahlen, T. F., and Jones, B. D. (2001). Fis, a DNA nucleoid-associated protein, is involved in Salmonella typhimurium SPI-1 invasion gene expression. Mol. Microbiol. 39, 79-88. doi: 10.1046/j.1365-2958.2001.02192.x

Winter, S. E., Thiennimitr, P., Winter, M. G., Butler, B. P., Huseby, D. L., Crawford, R. W., et al. (2010). Gut inflammation provides a respiratory electron acceptor for Salmonella. Nature 467, 426-429. doi: 10.1038/nature09415

Wozniak, C. E., Lee, C., and Hughes, K. T. (2009). T-POP array identifies EcnR and PefI-SrgD as novel regulators of flagellar gene expression. J. Bacteriol. 191, 1498-1508. doi: 10.1128/JB.01177-08

Yamamoto, S., and Kutsukake, K. (2006). FliT acts as an anti-FlhD2C2 factor in the transcriptional control of the flagellar regulon in Salmonella enterica serovar typhimurium. J. Bacteriol. 188, 6703-6708. doi: 10.1128/JB.00799-06

Yanagihara, S., Iyoda, S., Ohnishi, K., Iino, T., and Kutsukake, K. (1999). Structure and transcriptional control of the flagellar master operon of Salmonella typhimurium. Genes Genet. Syst. 74, 105-111. doi: 10.1266/ggs.74.105

Young, G. M., Badger, J. L., and Miller, V. L. (2000). Motility is required to initiate host cell invasion by Yersinia enterocolitica. Infect. Immun. 68, 4323-4326. doi: 10.1128/IAI.68.7.4323-4326.2000

Young, G. M., Smith, M. J., Minnich, S. A., and Miller, V. L. (1999). The Yersinia enterocolitica motility master regulatory operon, flhDC, is required for flagellin production, swimming motility, and swarming motility. J. Bacteriol. 181, 2823-2833.

Zhang, W., Wang, Y., Song, Y., Wang, T., Xu, S., Peng, Z., et al. (2013). A type VI secretion system regulated by OmpR in Yersinia pseudotuberculosis functions to maintain intracellular pH homeostasis. Environ. Microbiol. 15, 557-569. doi: 10.1111/1462-2920.12005

Zhang, X., Kelly, S. M., Bollen, W. S., and Curtiss, R. III (1997). Characterization and immunogenicity of Salmonella typhimurium SL1344 and UK-1 delta crp and delta cdt deletion mutants. Infect. Immun. 65, 5381-5387.

Zhang, Y. J., and Rubin, E. J. (2013). Feast or famine: the host-pathogen battle over amino acids. Cell. Microbiol. 15, 1079-1087. doi: 10.1111/cmi.12140

Conflict of Interest Statement: The authors declare that the research was conducted in the absence of any commercial or financial relationships that could be construed as a potential conflict of interest.

Copyright ( $\odot 2015$ Erhardt and Dersch. This is an open-access article distributed under the terms of the Creative Commons Attribution License (CC BY). The use, distribution or reproduction in other forums is permitted, provided the original author(s) or licensor are credited and that the original publication in this journal is cited, in accordance with accepted academic practice. No use, distribution or reproduction is permitted which does not comply with these terms. 